\author{
دراسة التجمعات ورسم وتوصيف سلاسل القيمة في القطاعات \\ الاقتصادية الرئيسية في محافظة الفيوم \\ إيناس السيد صادق محمد \\ قسم الاقتصاد الزراعي- كلية الزراعةـ جامعة الفيوم
}

تمتاز محافظة الفيوم بالعديد من المقومات التنموية التي تؤهل المحافظة لتحقيق معدلات تنمية

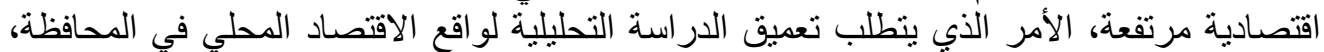

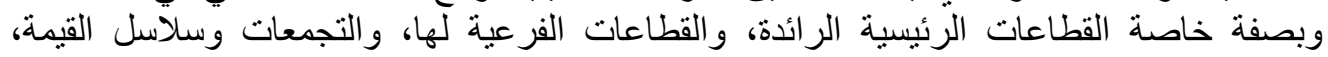

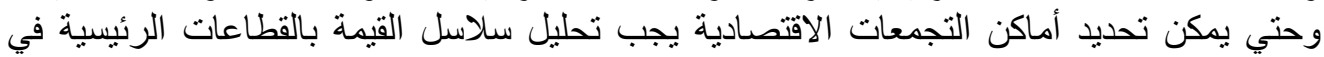

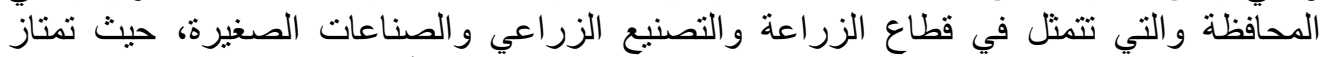

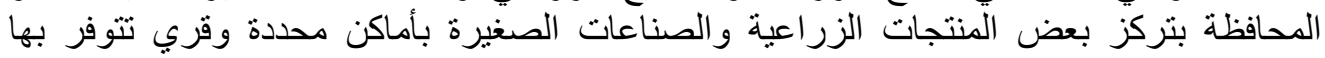

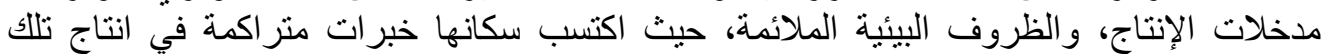

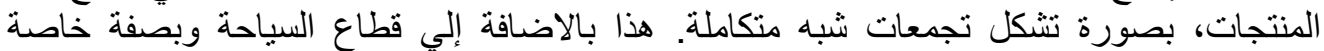

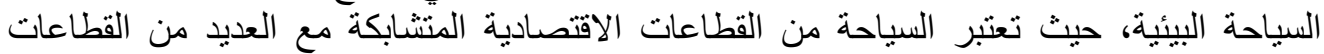

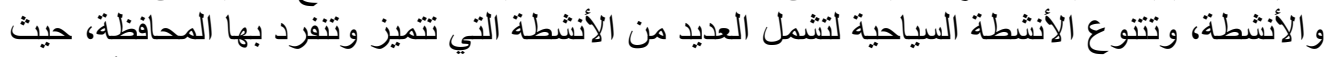

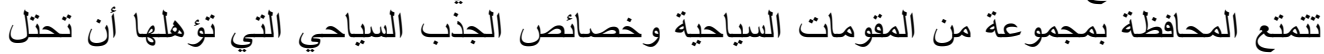

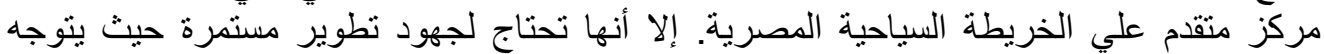

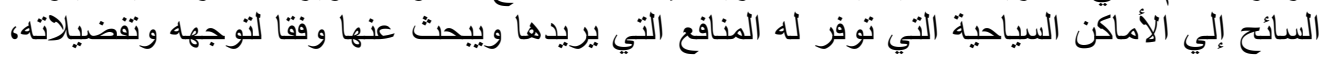

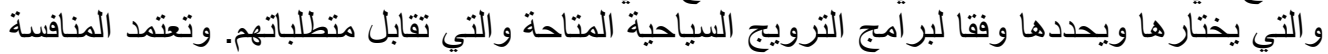

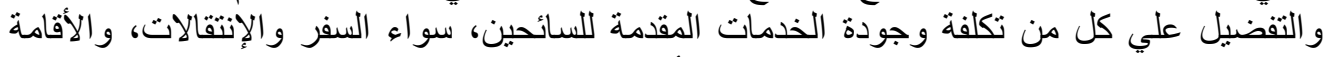

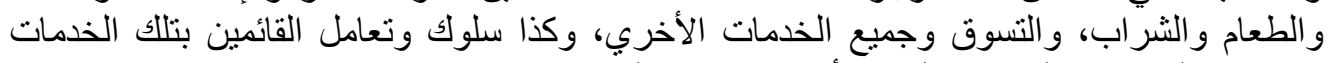
و الارشاد السياحي و الفندقة، والبنية الأساسية وتوفر الخدمات و الاتصالات.

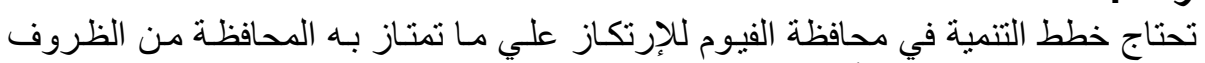

مشكلة الار اسة:

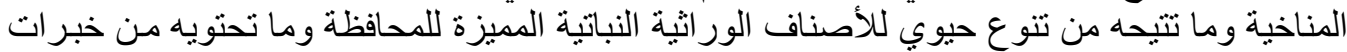

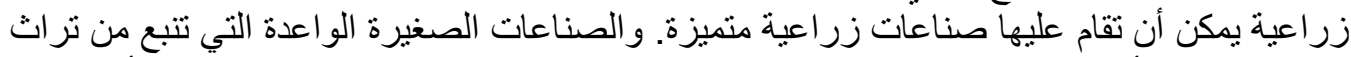

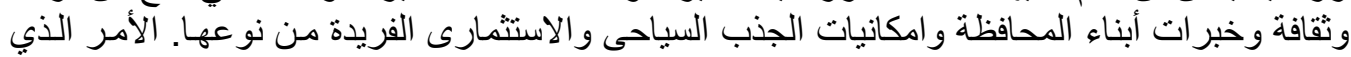

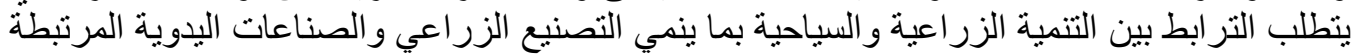

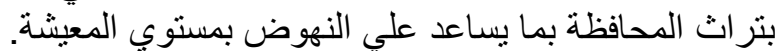

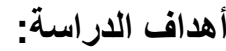

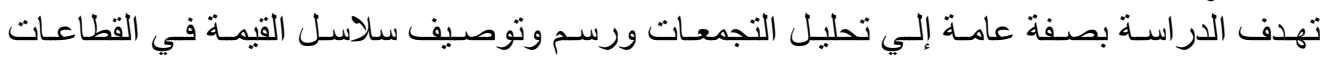

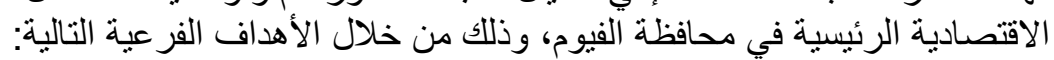

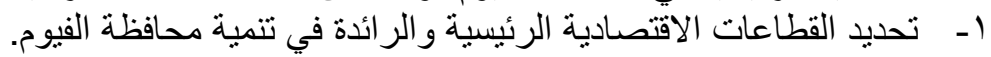

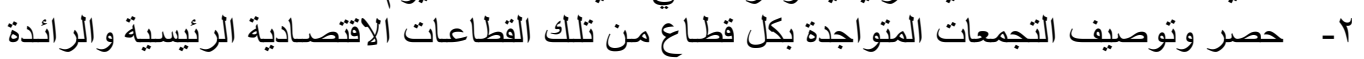
في تنمية محافظة الفيوم.

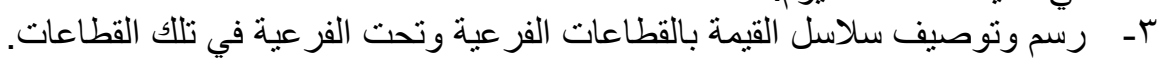
ع - وضع تصور التقوية سلاسل القيمة بما يساعد علي رفع مستوي المعيثة بالمحافظة.

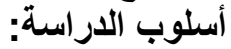

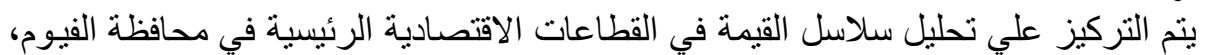

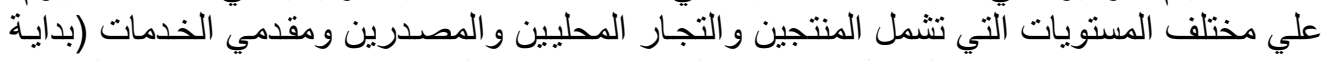

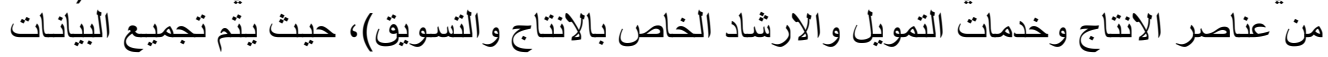

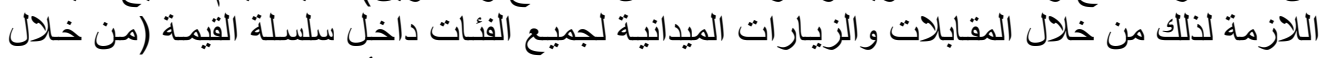

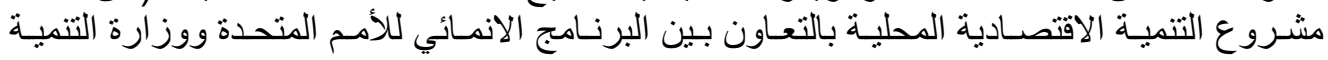

Fayoum J. Agric. Res. \& Dev., Vol. 26, No.2, July, 2012 
المحلية وجامعة الفيوم)، وذللك لتحليل مدي التعقيد و التر ابط والتنسيق بين مختلف الفئات داخل سلسلة القيمة، وتحديد مناطق الضعف وجة و القوة و الفرص و و التهديدات.

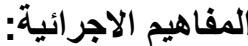

يعتمد تحليل سلاسـل القيمـة بتلك القطاعـات علي مختلف المستويات التي تشـمل المنتجين و التجار المحليين و المصدرين ومقدمي الخدمات (بداية من عناصر الانتاج وخدمات آلتمويل و الارشـاد

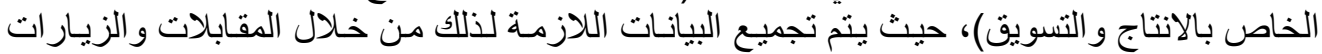
الميدانية لجميع الفئات داخل سلسلة القيمة، وذلك لتحليل مدي التعقيد و الترابط و التنسيق بينهم، وتحديد مناطق الضعف والية لجميع القوة و الفرص داخ و التهديدات.

أولا: التجمعات ورسم وتوصيف سلاسل القيمة Clusters \& Mapping Value Chain

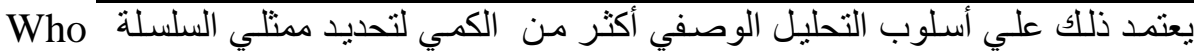

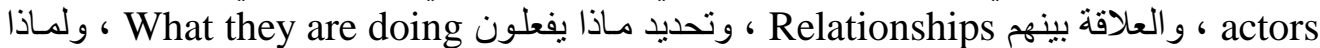

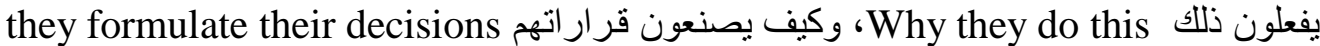
and how

هذا بالإضـافة إلـي البيئة الممكنة Enabling environment من بنيـة أساسية وسياسـات ومقدمي الخدمات و الارشاد Service providers. ويشمل ممثلي السلسلة الحلقات التالية (13):

Input Suppliers $\rightarrow$ Farmers $\rightarrow$ Traders $\rightarrow$ Processors $\rightarrow$ Exporters/ importers $\rightarrow$ Retailers $\rightarrow$ Consumers

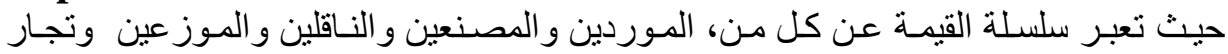

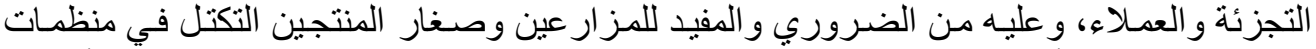

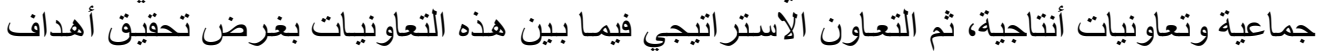

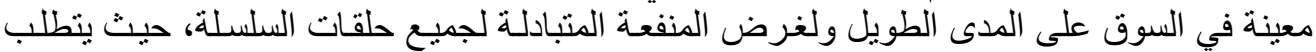

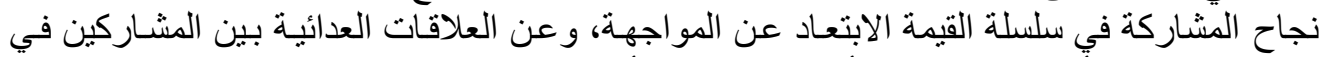

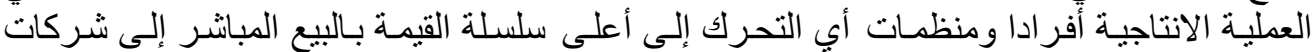

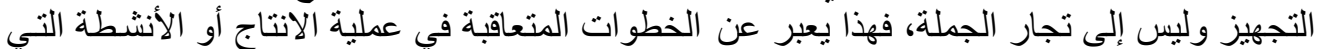

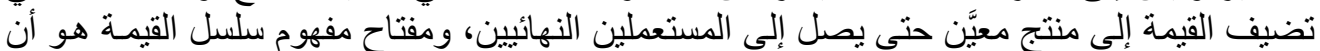

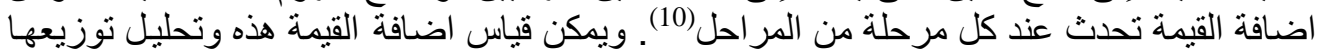

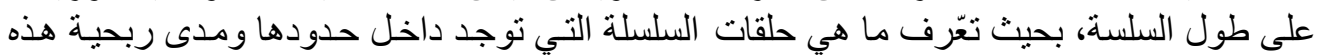

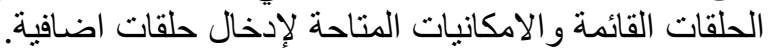

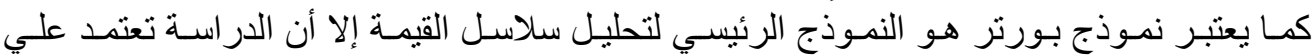

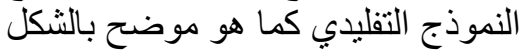

ويوضح شكل رقم ( ) نموذج تقليدي لسلاسل القيمة(14)

Fayoum J. Agric. Res. \& Dev., Vol. 26, No.2, July, 2012 


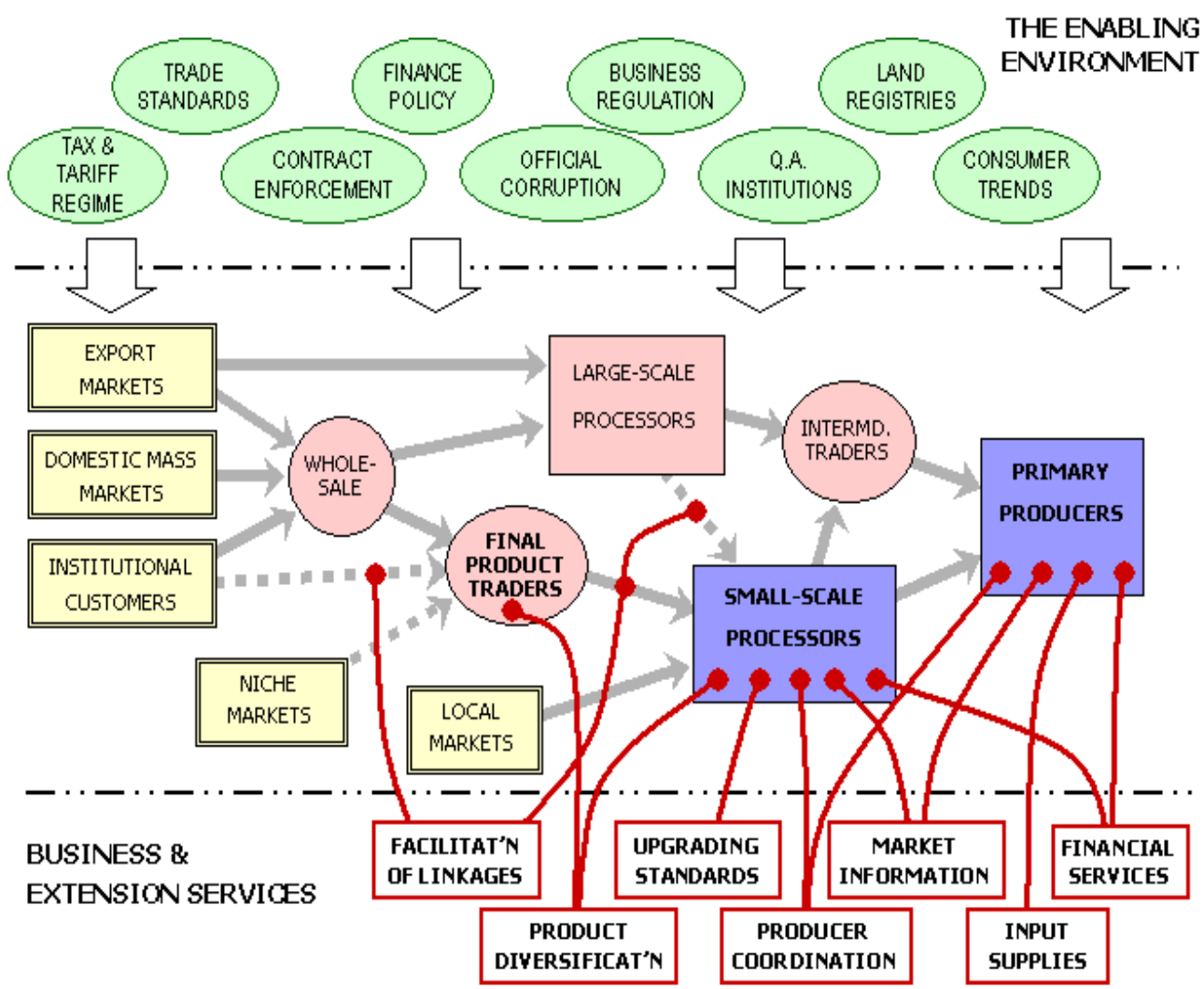

Source: Value Chain Mapping Report, Upgrading Medicinal and Aromatic Plants Value Chain Access to Export Markets, UNIDO/ETRACE, July 2011.

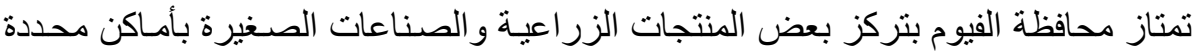
نتائج الاراسة:

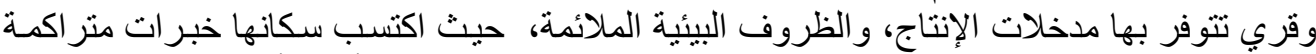

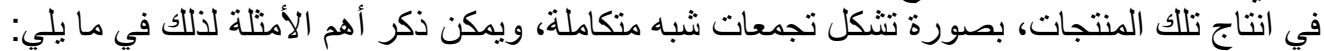

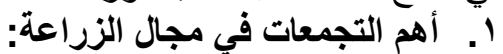

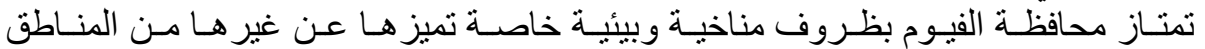

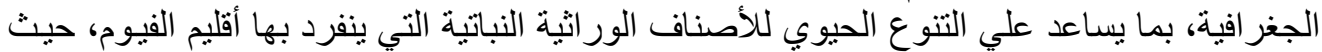

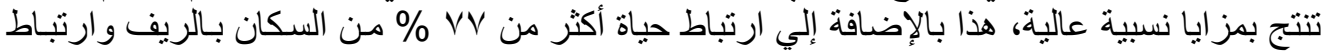

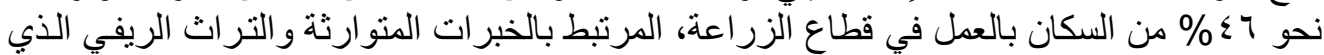

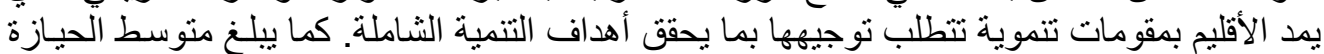

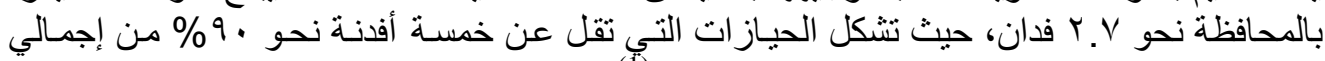

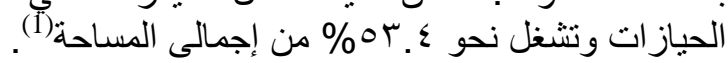
1-1 أهم التجمعات في مجال إنتاج النباتات الطبية والعطرية:

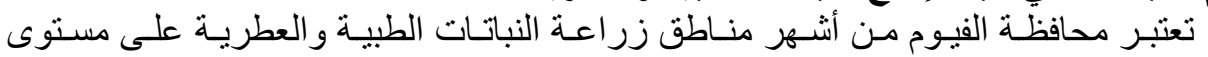

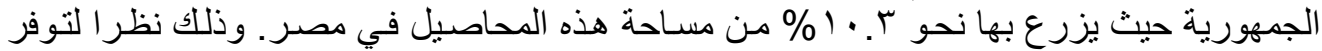

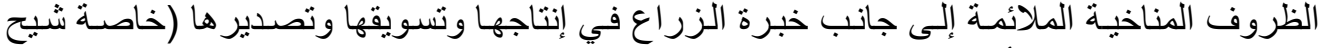
البابونج و البردقوش و الأقحوان و العتر و النعناع وحشيشة الليمون والريحان فالئ و الانتجت و غير ها).

Fayoum J. Agric. Res. \& Dev., Vol. 26, No.2, July, 2012 
وتوجد العديد من جمعبات صــار المنتجين تقدم خدمات الانتاج وتقوم بعملية تسويق منتجـات

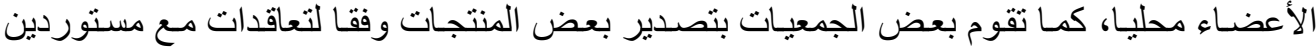

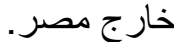

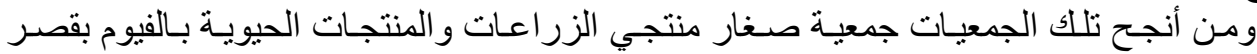

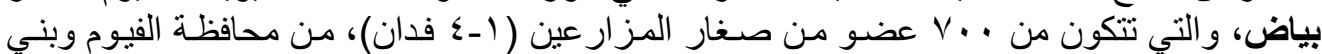

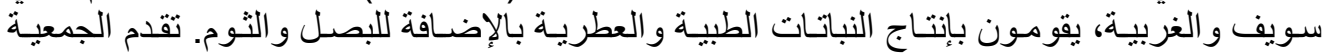

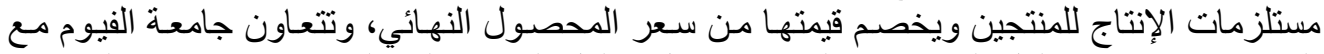

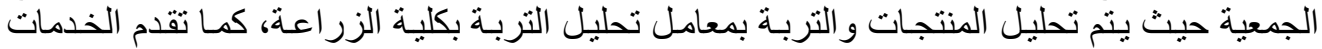
الارشادية التي يحتاج إليها أعضاء الجمئة الجمعية.

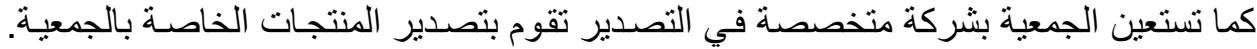

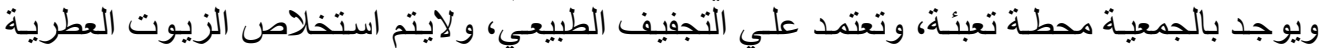

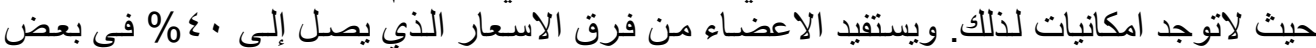

كما توجد جمعيات بكل من قرية تلات ومنشاة سكر ان وأبو جنشو، حيث يوجد نحو ر ب مصدر

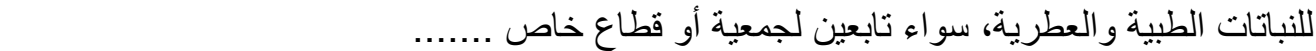

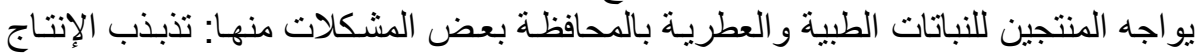
و الأسعار، وتحكم عدد من التجار في تسويق تللك المنتجات، هذا بالإضـافة إلي الاعتمـاد علي تصدير

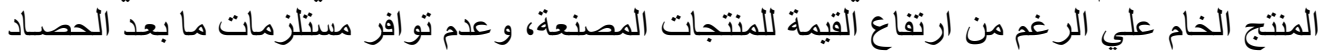

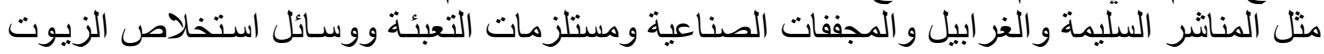

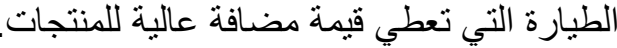
ا ـ ـ ـ سلاسل القيمة في النباتات الطبية والعطرية في في محافظة الفيوم كما يلي:

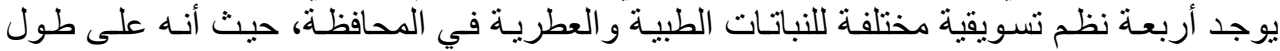

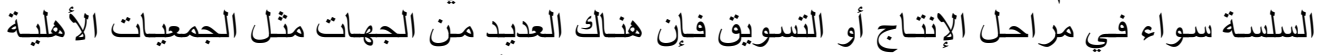

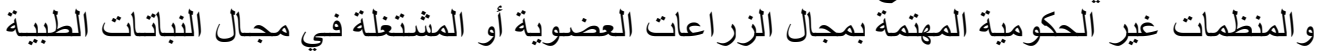

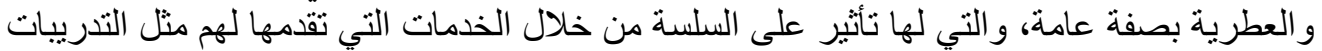

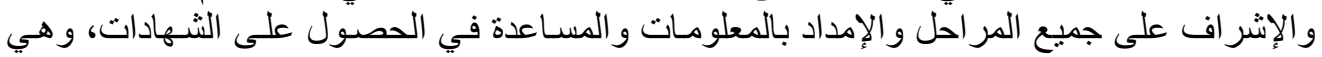

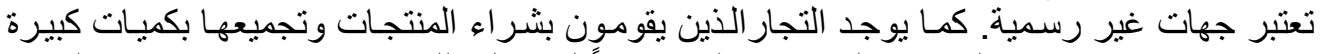

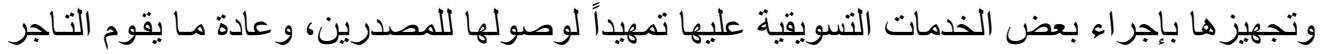

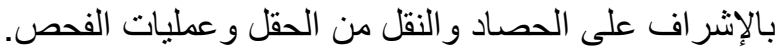
و المصدرين الذين يمثلون الحلقة الأخيرة للمتعاملين في السلسة، ويقومون بإجر اء ما بلزئم من خدمات

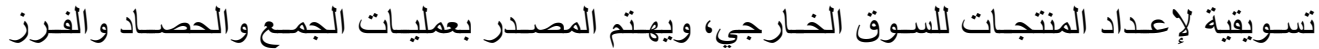
و التجفيف، و التعبئة حسب طلب كل جهة، وقد يقوم المصدرر نفسـه بهذه العمليات أو يقوم بالإشـر اف وفئ

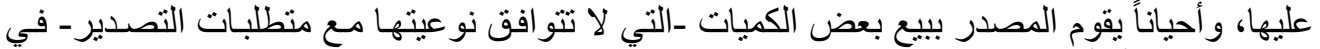
السوق المحلي (16). يوضح شكل رقم (Y) تعدد سلاسل القيمة لتأخذ نحو أربعة أشكال رئيسية في النباتات الطبية و العطرية بالمحافظة كما يلي:

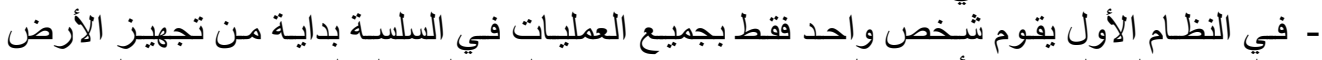

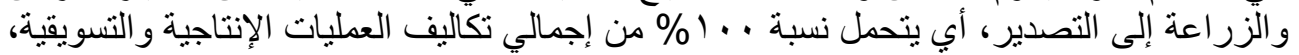

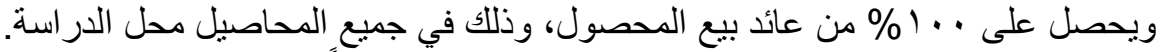

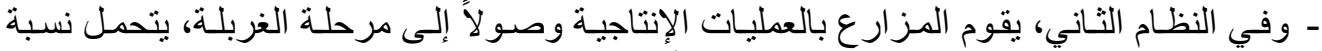

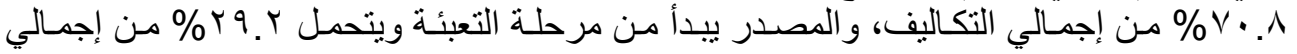

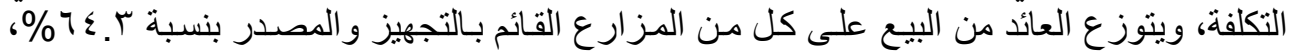

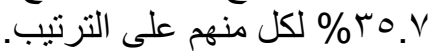

Fayoum J. Agric. Res. \& Dev., Vol. 26, No.2, July, 2012 
74

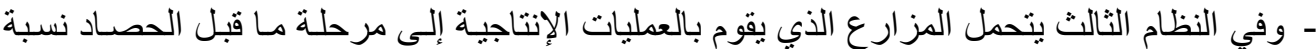

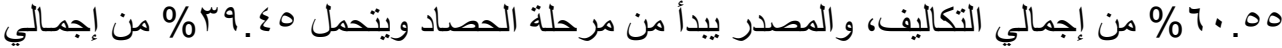

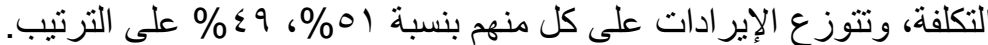

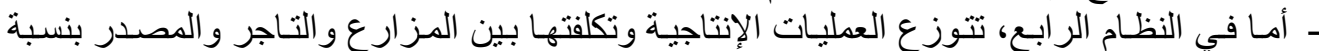

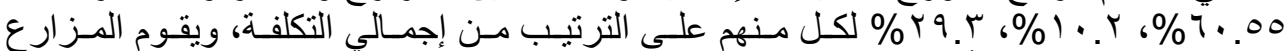

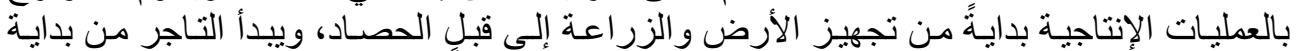

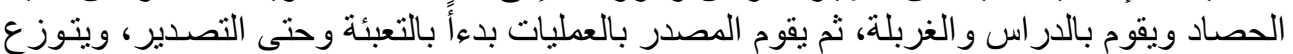

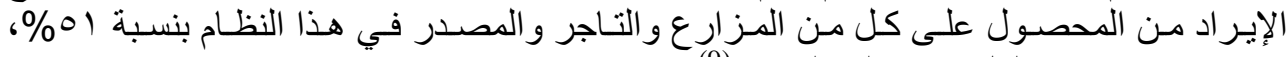

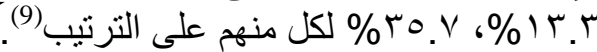

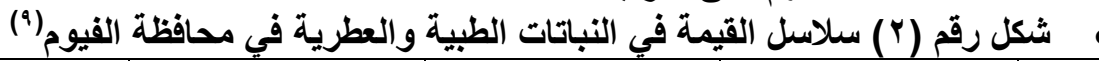

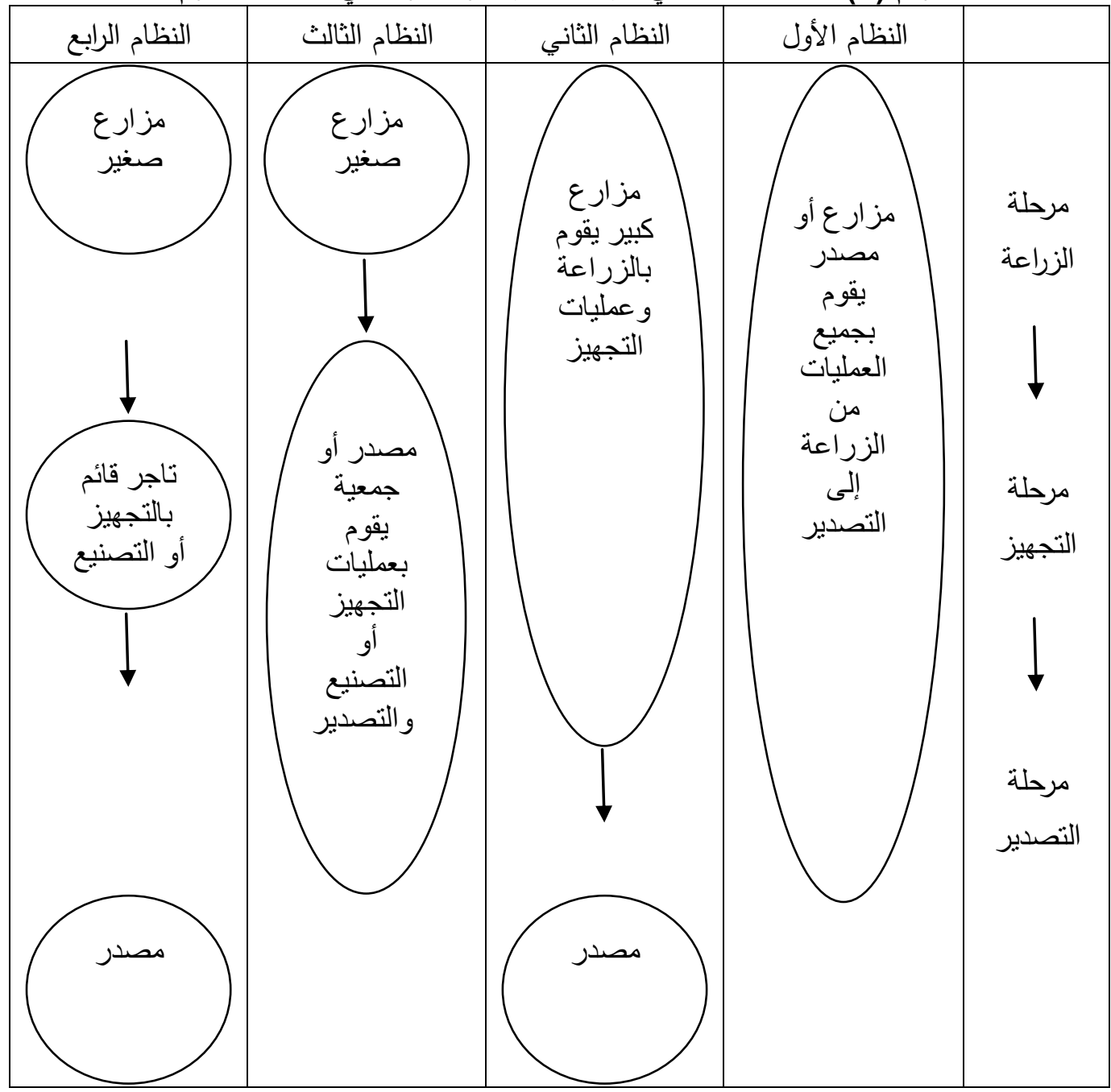

المصدر: تم تصميم الثكل من واقع المقابلات والزيارات الميدانية لجميع الفئات داخل سلسلة القيمة

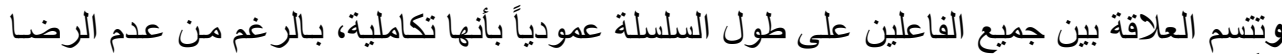

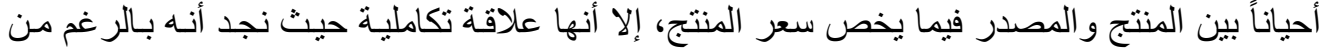

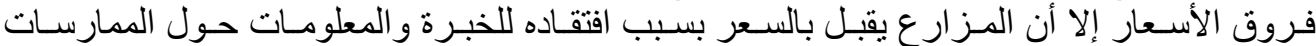

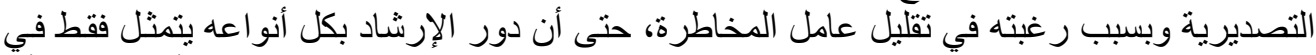

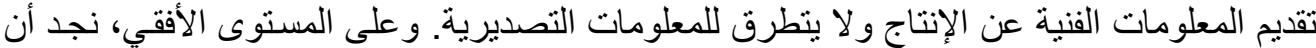

Fayoum J. Agric. Res. \& Dev., Vol. 26, No.2, July, 2012 
TV

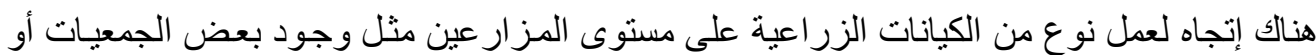

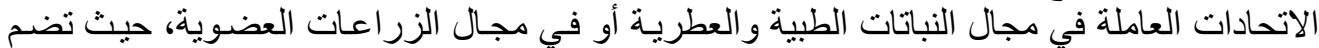

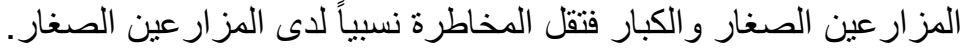

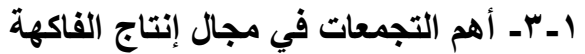

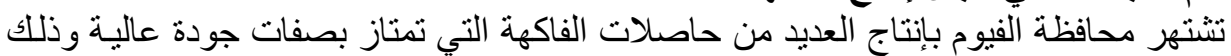

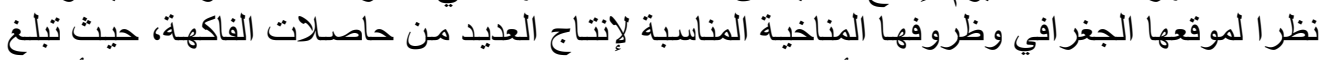

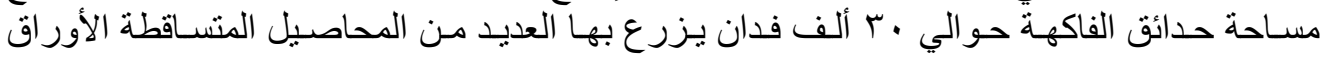

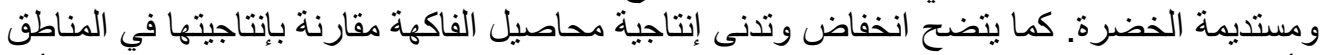

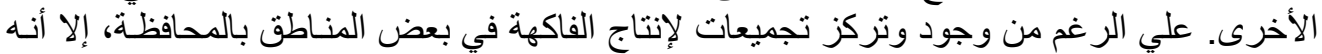

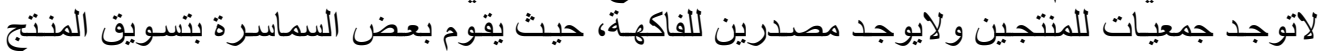

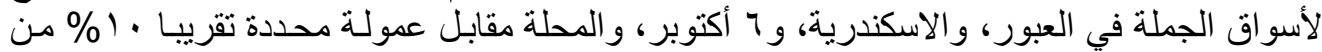
قيمة الانتاج، أو فرز واختيار المنتج الصالح للتصدير وفقا لمو اصفات محدده وتوريده للمصدر خـارج المحافظة الانتاج

ويرجع ذلك إلى العديد من المشاكل التي تواجه زر اعة و إنتاج بساتين الفاكهة بالفيوم أهمها:

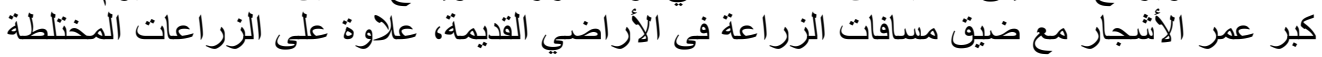

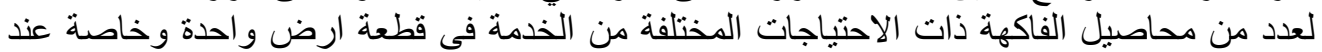

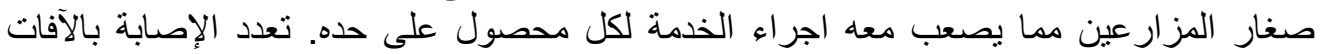

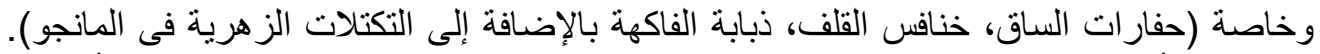

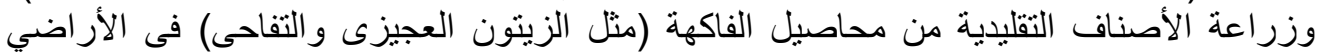

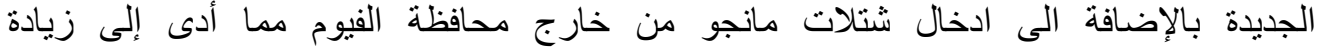

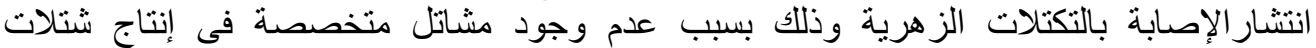

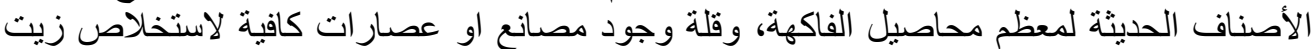

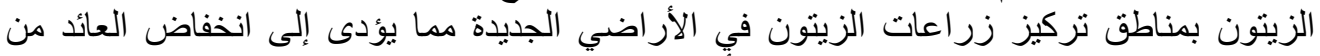

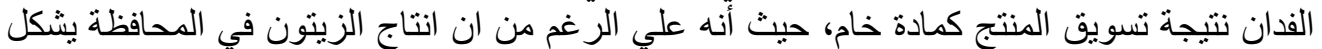

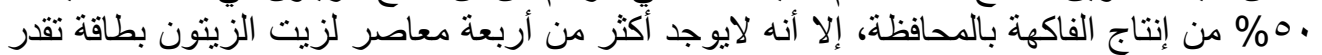

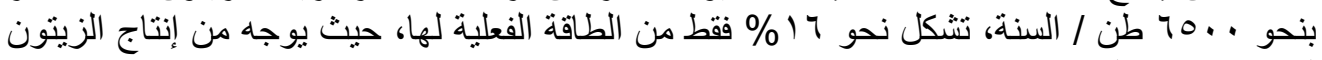

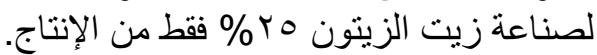

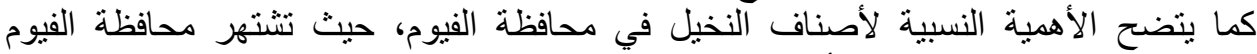

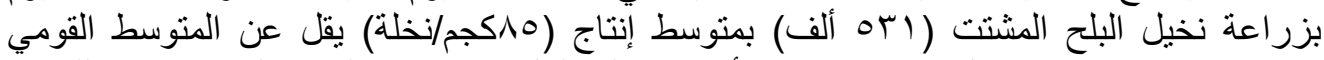

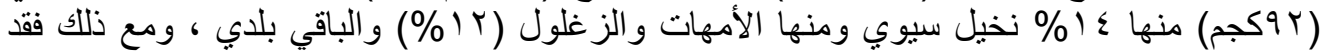

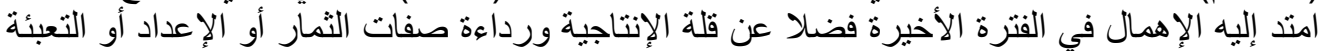

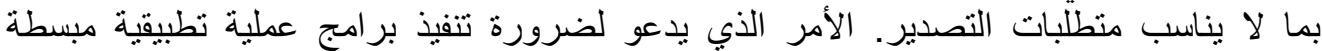

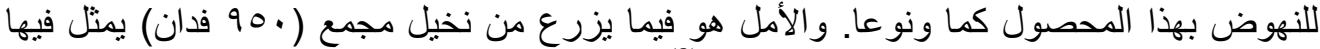

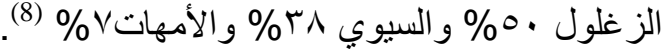

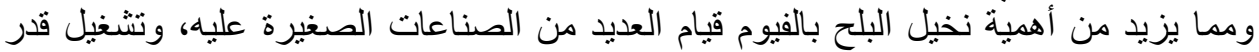

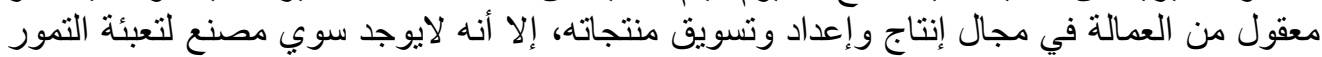

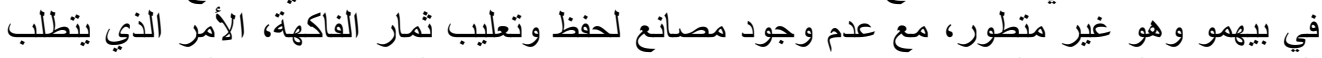

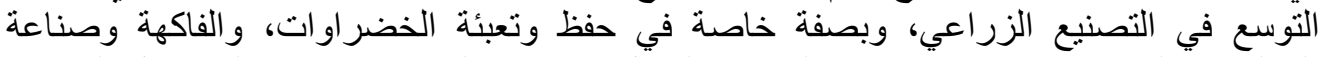

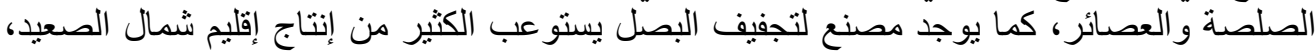

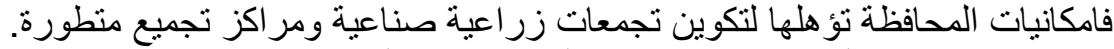
1 ـ ـ ـ سلاسل القيمة للخضروات التهات والفاكهة في المحافظة كما يلي:

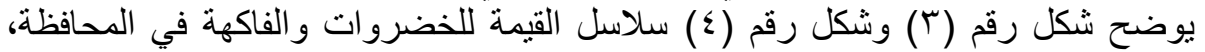

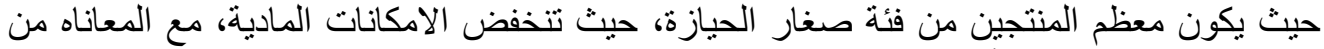
نقص في المعلومات و الأرشادات الفنية وبصفة خاصة لمعاملات مابعد الحصاد، حيث لاتوجد جهة التهانة

Fayoum J. Agric. Res. \& Dev., Vol. 26, No.2, July, 2012 
71

توفر مدخلات الإنتاج كالأسمدة والأصناف الملائمة، بالإضافة إلي ندرة العمالة الماهرة اللازمة لاداء

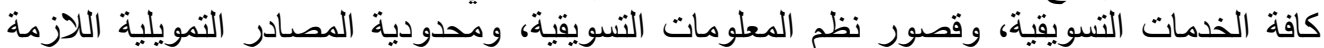
للقيام بالعمليات التسويقية المختلفة التي تجرى على على أغلب الحاصلات التهات البستانية. كما لاتوجد جمعيات للمنتجين ولايوجد مصدرين للفاكهة بالمحافظة، حيث يقوم بعض السفة السماسرة بتسويق المنتج لأسواق الجملة في العبور، و الاسكندرية، و 7 أكتوبر، و المحلة مقابل عمولة محددة

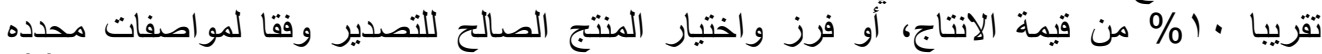

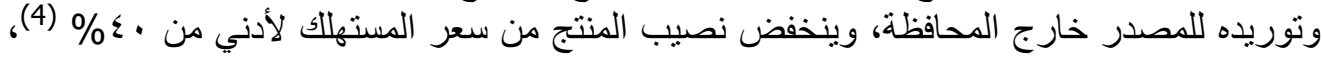

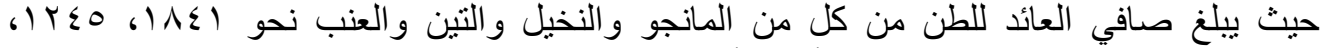

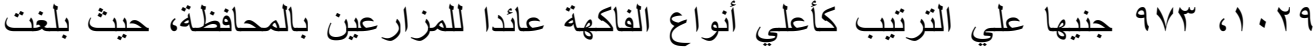

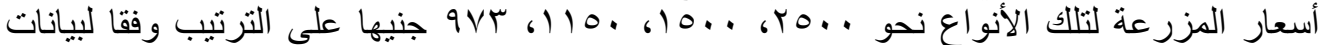

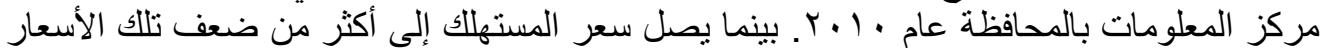

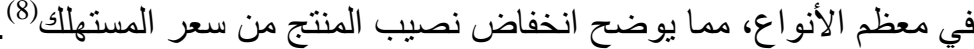

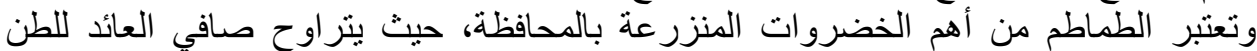

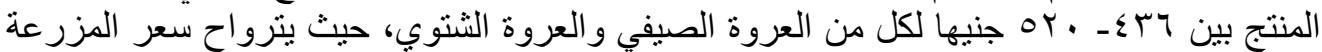

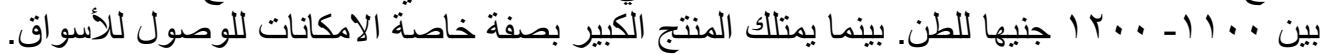

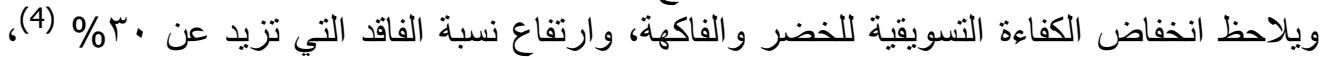

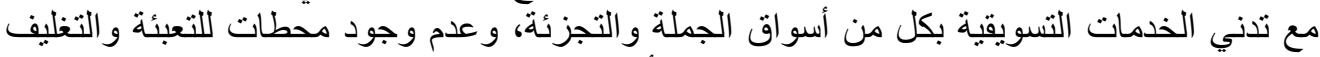

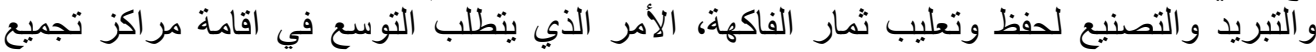

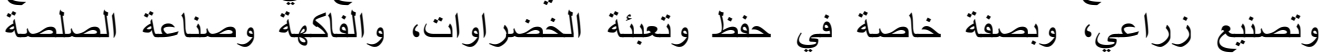

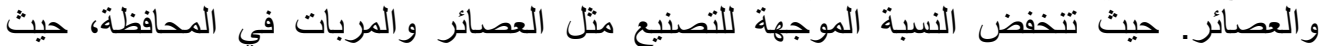

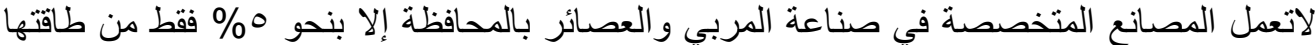
الأنتاجية، بينما تنخفض النسب الموجهة للحفظ بالتجفيف و التجميد من الخضر و الفاكهة بالمحافظة،

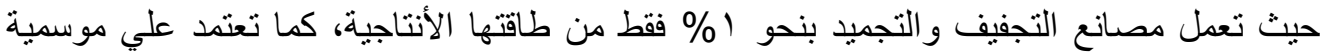
الإنتاج في فترة محدودة جدا ترتبط بالخضرو ات والفاكهة التي تحفظها.

Fayoum J. Agric. Res. \& Dev., Vol. 26, No.2, July, 2012 


\section{Mapping Fruit Value Chain}

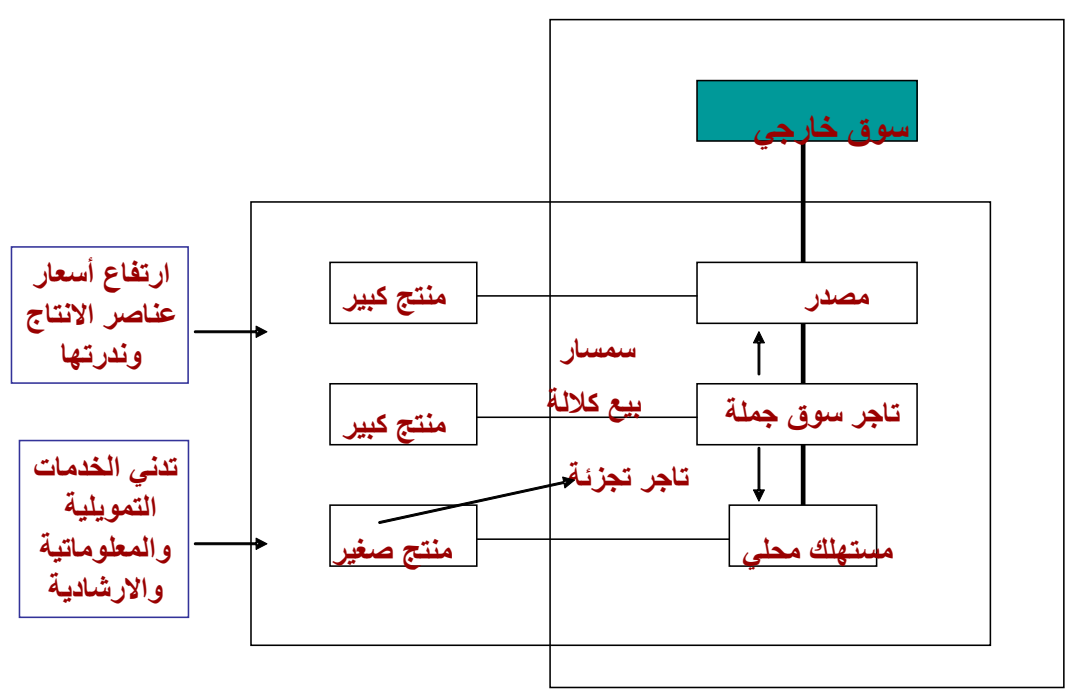

المصدر : نم تصميم الشكل من واقع المقابلات والزيارات الميدانية لجميع الفئات داخل سلسلة القيمة

1 - أهـ أهم التجمعات في مجال الانتاج الحيواني

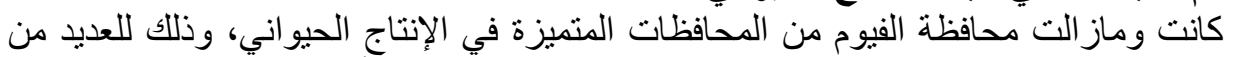

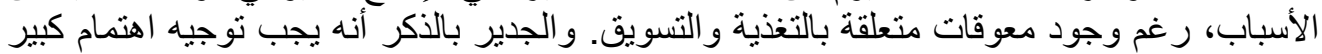

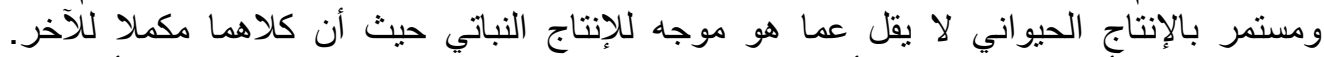

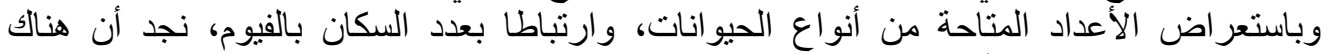

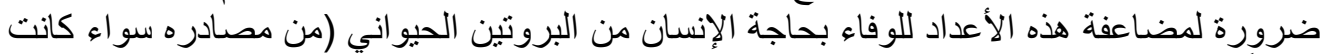

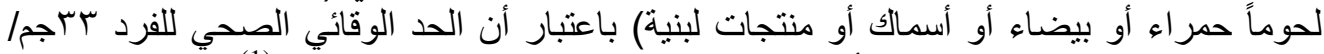

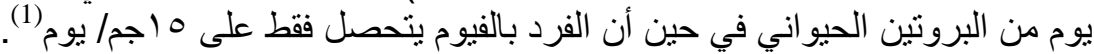

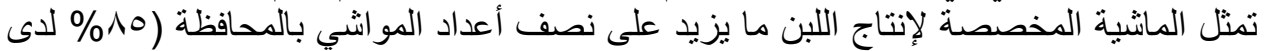

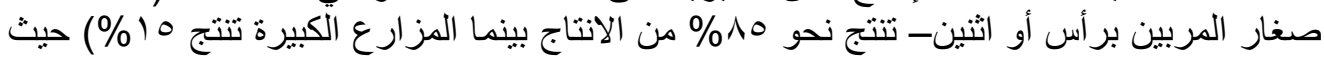

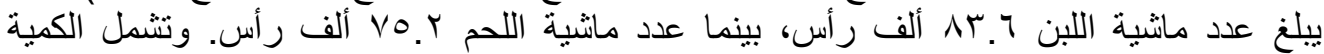

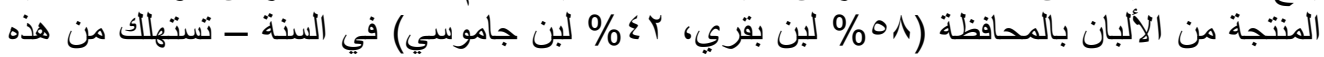

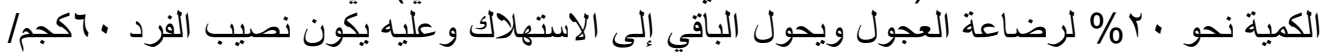

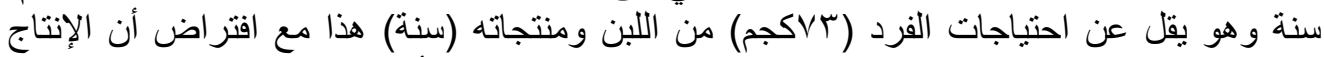

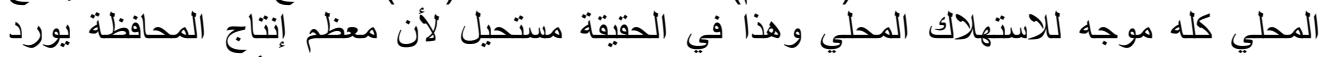

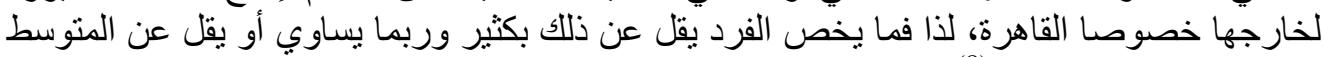

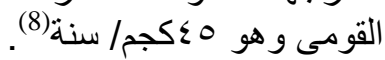

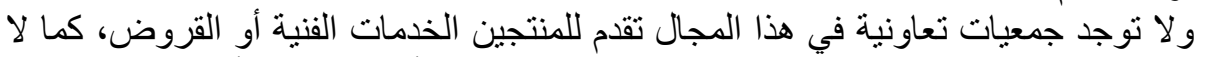

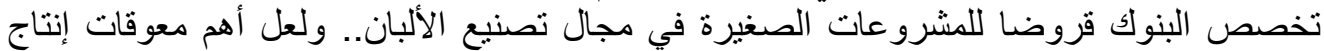

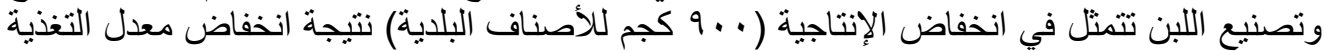

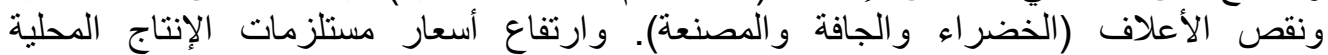
و المستوردة وبالتالي تكلفة الإنتاج ، وبصفة خاصة الأعلاف حيث يوجد بالمحافظة 7 مصانع لإنتاج الإناج

Fayoum J. Agric. Res. \& Dev., Vol. 26, No.2, July, 2012 
V.

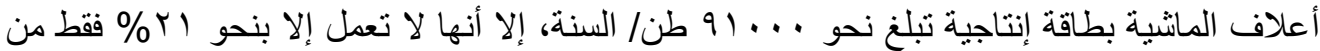

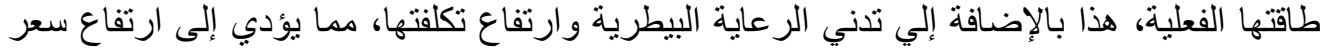

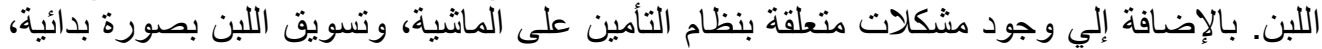

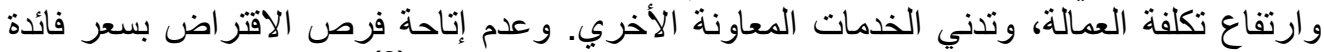

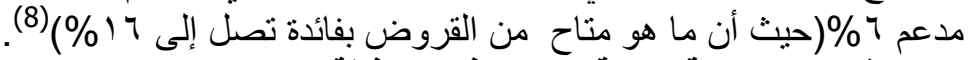

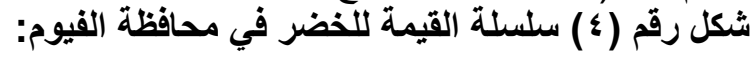

\section{Mapping Vegetable Value Chain}

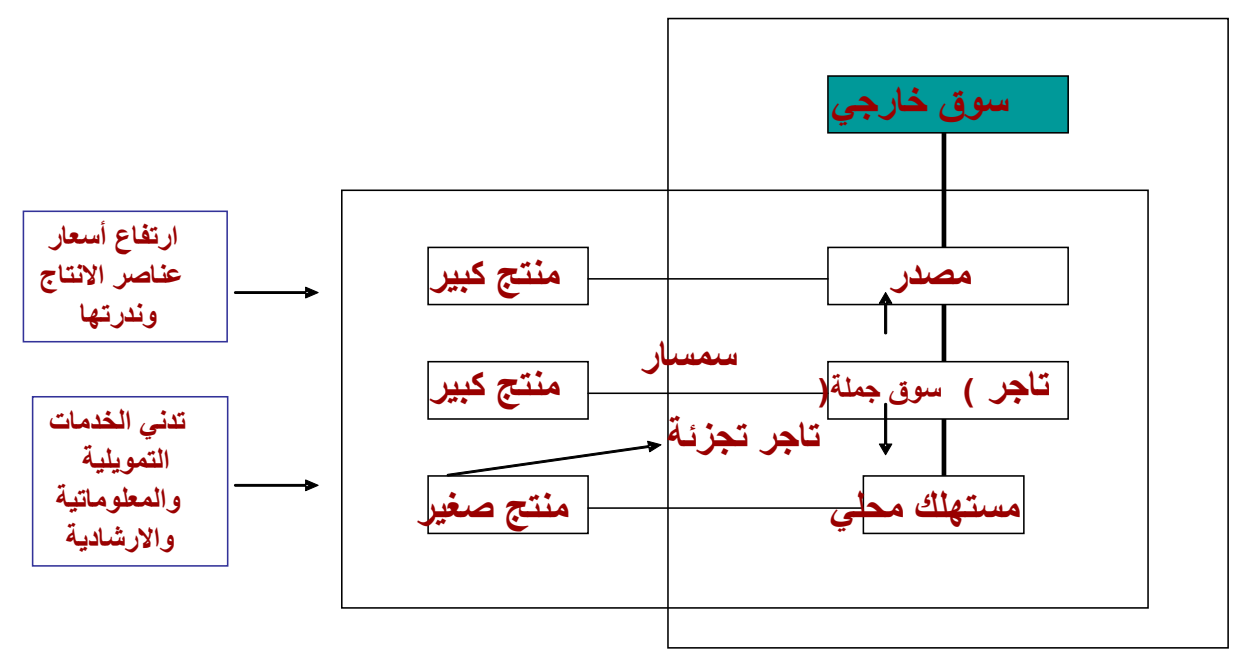

المصدر: تم تصميم الثكل من و اقع المقابلات و الزيار ات الميدانية لجميع الفئات داخل سلسلة القيمة

ا -7 - أهم التجمعات في مجال انتاج الدواجن عابن

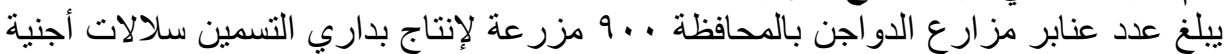

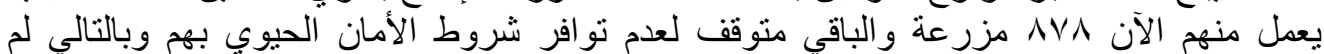

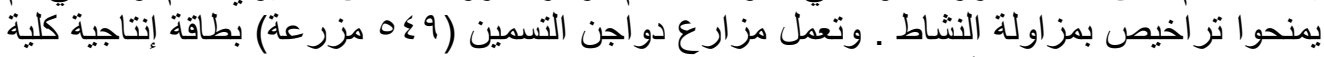

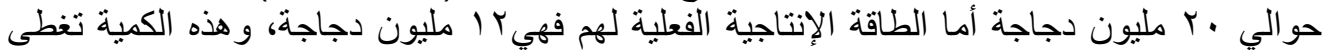

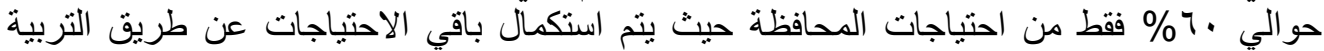
المنزلية او من المحافظات المجاورة، كما يبلغ انتاج بداري التسمين البلدي نحو 7 مليون دجاجة التهات تتنجها نحو

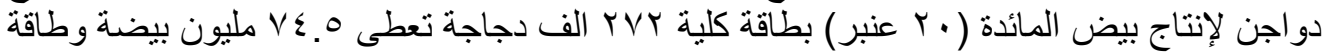

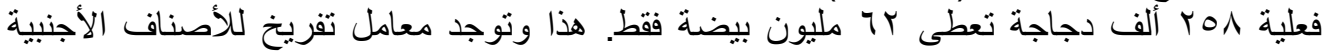

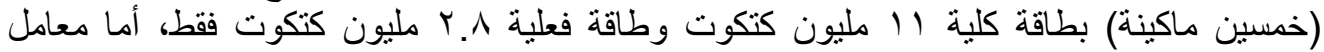

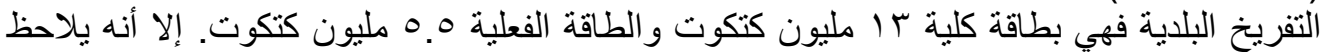

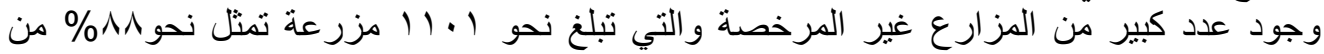

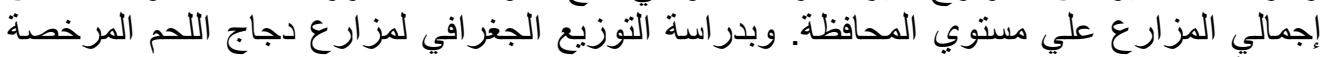

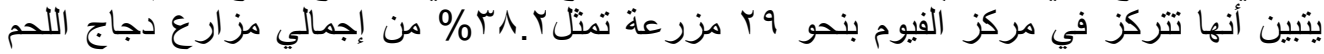

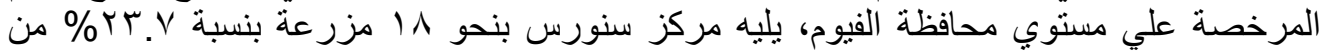

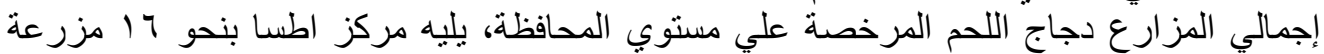
بنسبة 1. اب \% من إجمالي مزارع دجاج اللحم المرخصة علي مستوي المحافظة، ثم مركز طامية ،

Fayoum J. Agric. Res. \& Dev., Vol. 26, No.2, July, 2012 
VI

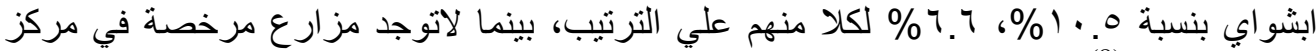
يو سف الصديق (8). (1).

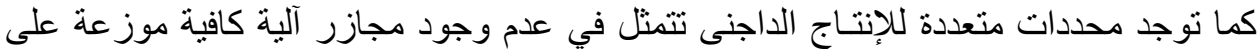

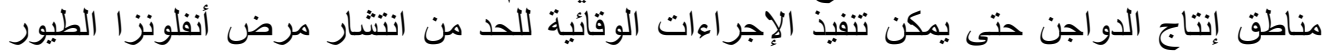

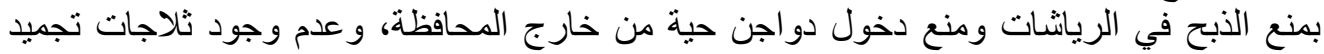

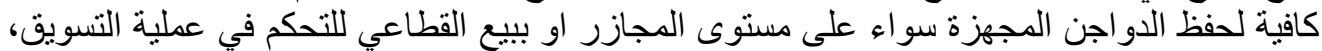

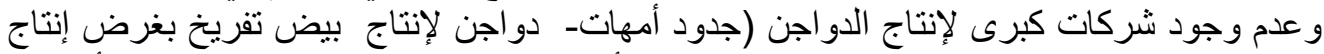

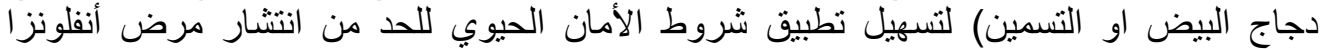

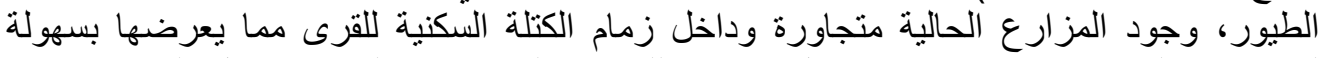

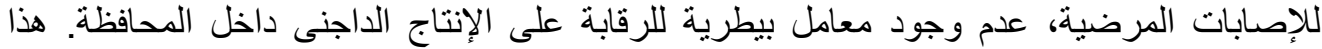

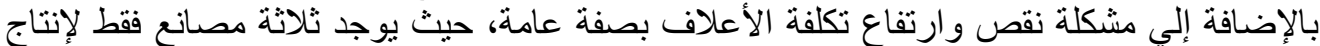

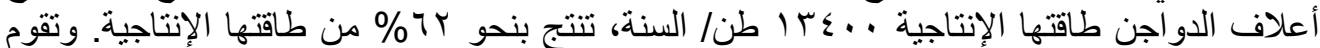

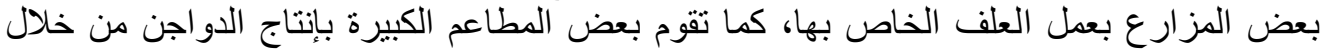

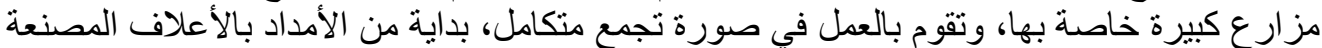

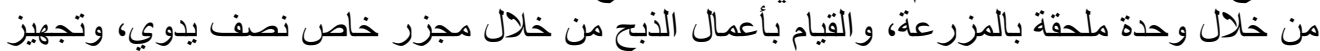

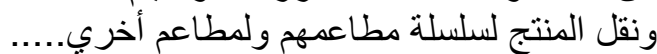

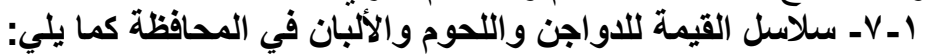

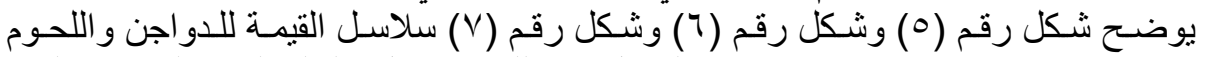

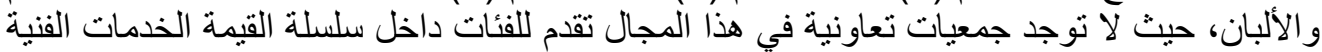

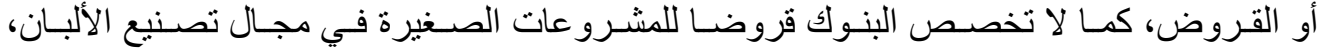

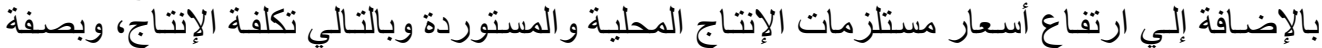

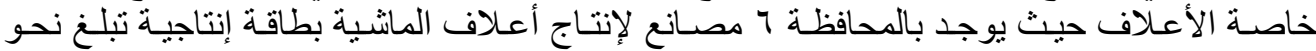

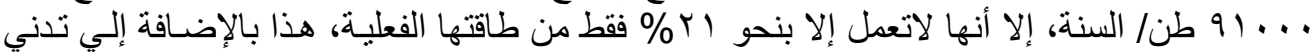

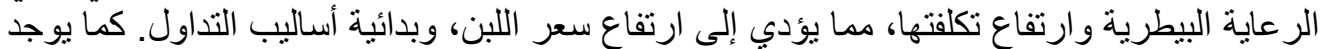

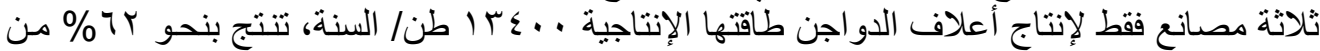

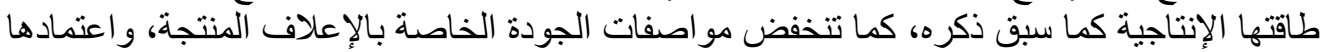

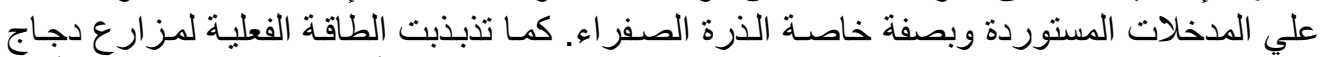

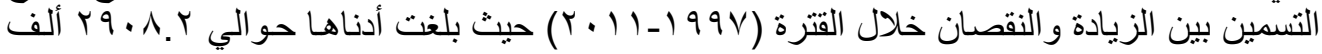

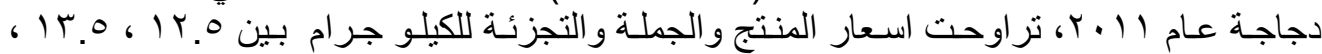

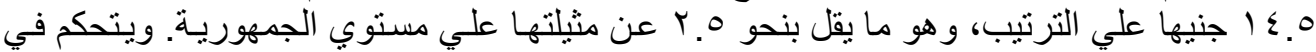

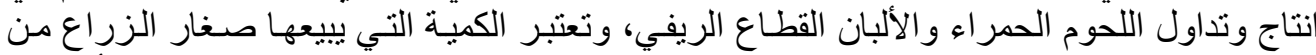

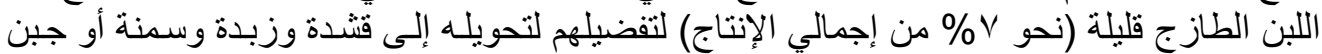

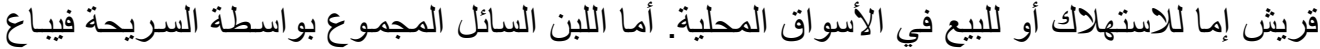

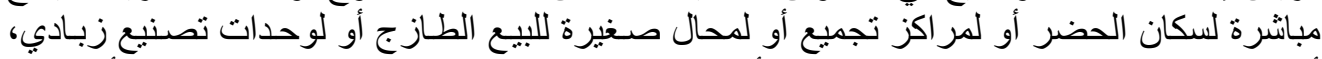

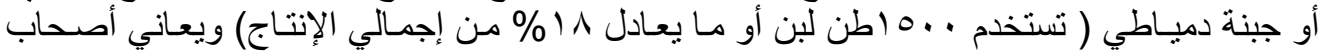

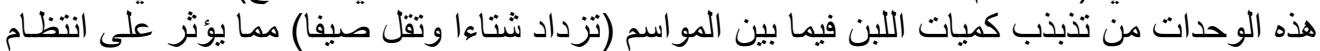

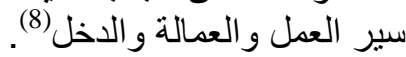

شكل رقم (•) سلسلة القيمة للاواجن في محافظة الفيوم

Fayoum J. Agric. Res. \& Dev., Vol. 26, No.2, July, 2012 


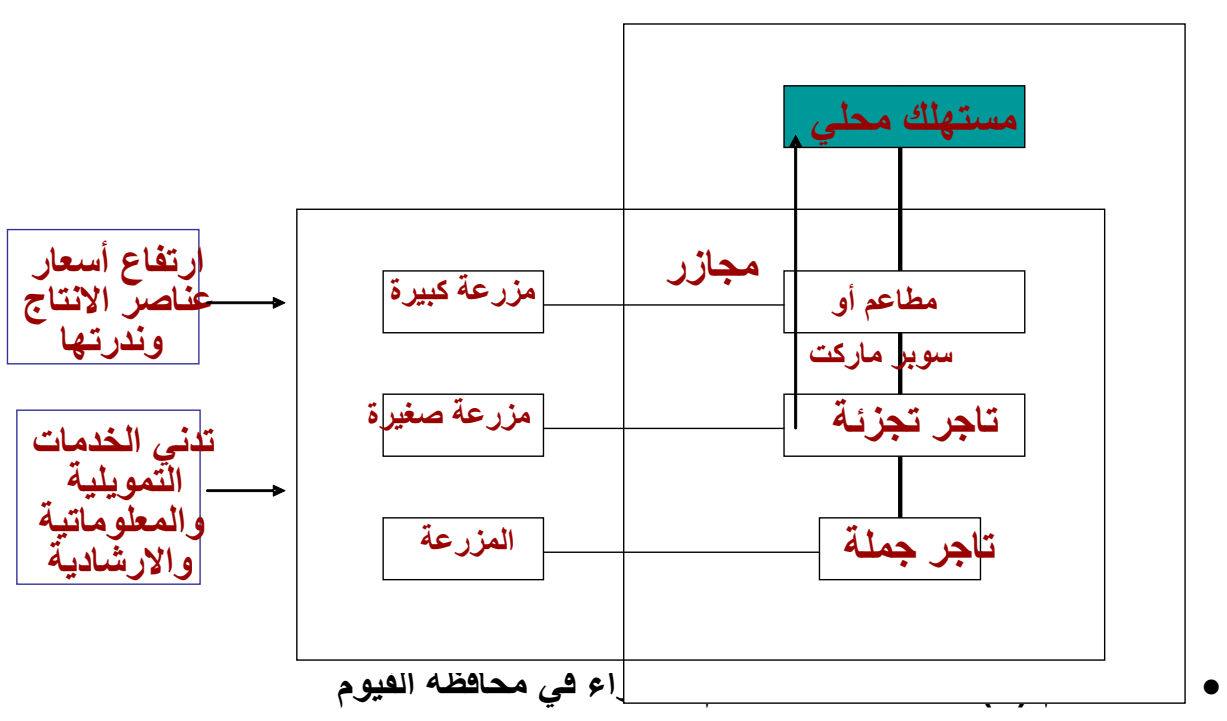

Mapping Meat Value Chain

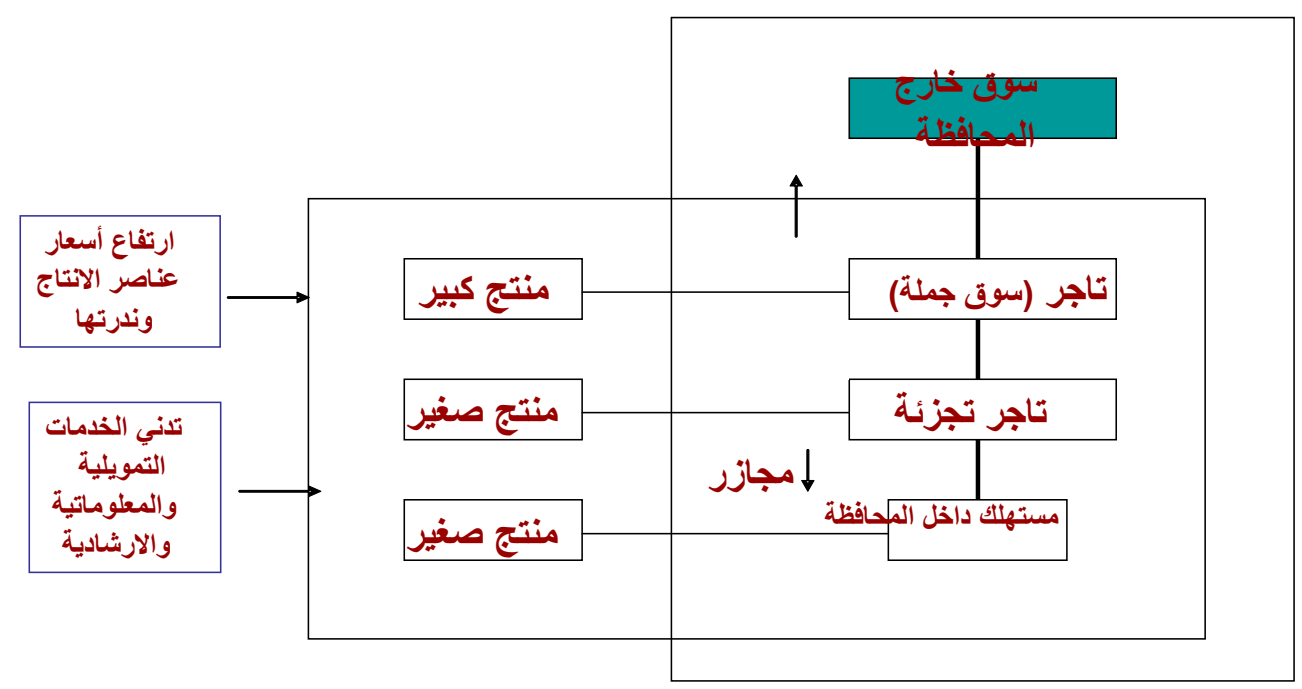

المصدر: تم تصميم الثكل من واقع المقابلات والزيارات الميدانية لجميع الفئات داخل سلسلة القيمة

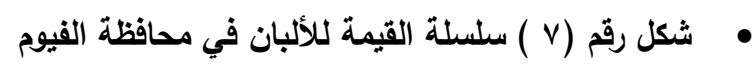

Fayoum J. Agric. Res. \& Dev., Vol. 26, No.2, July, 2012 


\section{Mapping Milk Value Chain}

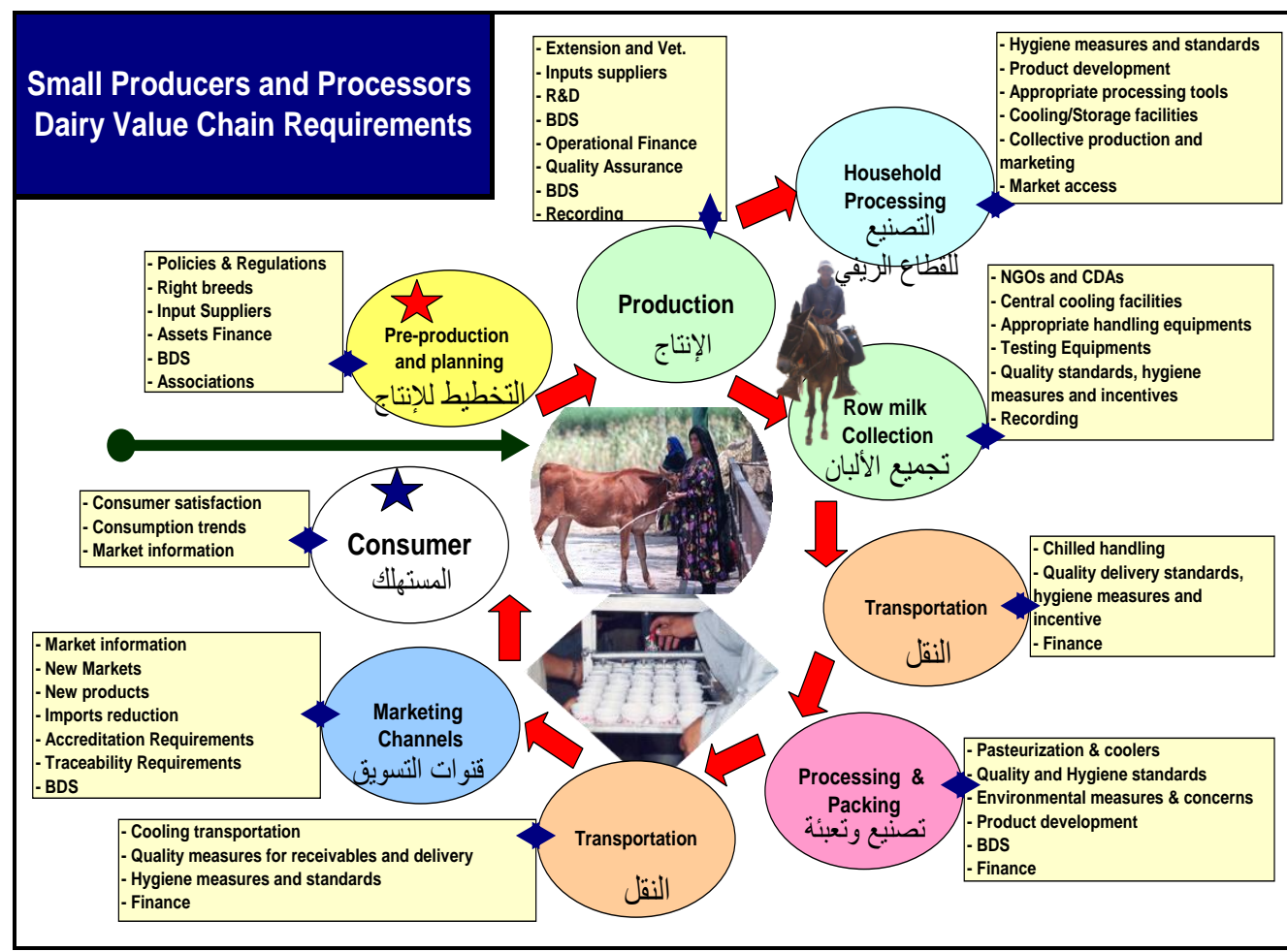

المصدر: تم تصميم الثكل من و اقع المقابلات و الزيار ات الميدانية لجميع الفئات داخل سلسلة القيمة

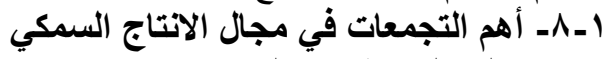

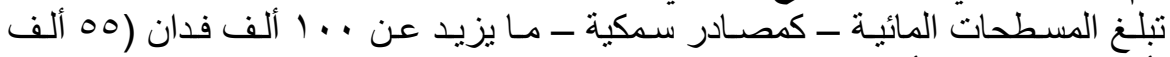

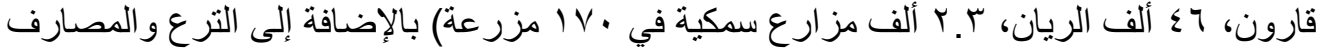

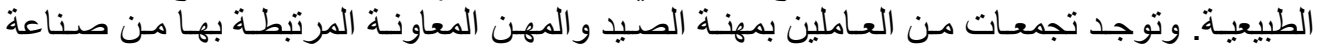

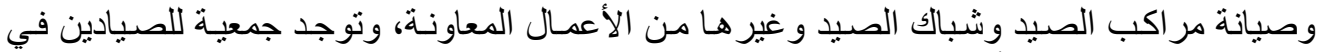

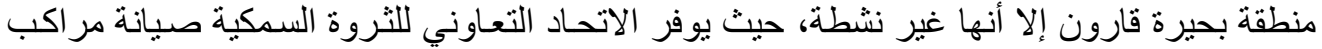

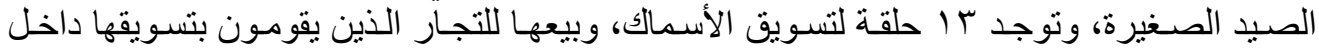

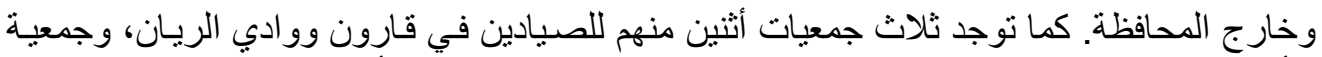

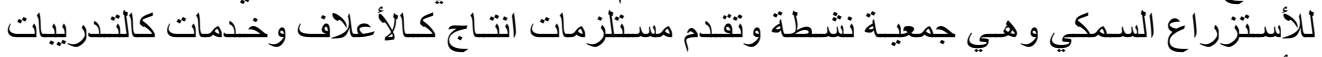

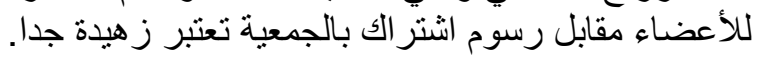

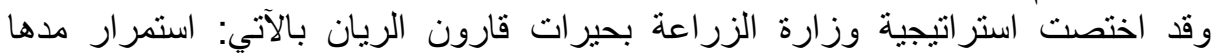

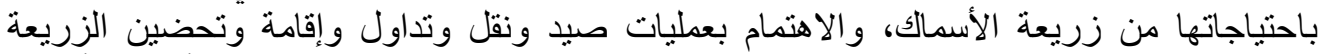

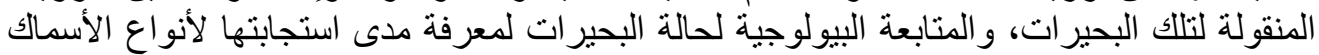

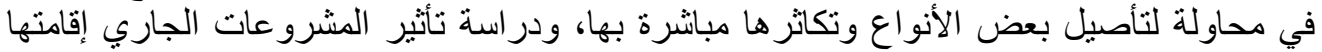

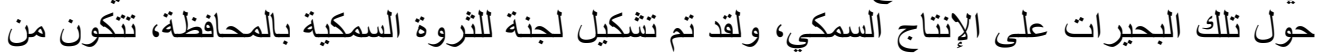

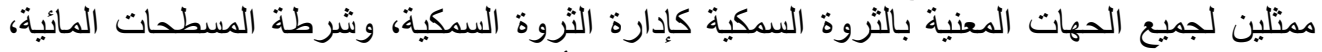

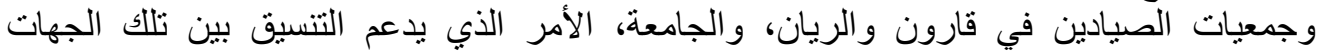
للتخطيط لتنمية الثروة السمكية في المحافظة وحل مشاكلها و النهوض والئ بها.

Fayoum J. Agric. Res. \& Dev., Vol. 26, No.2, July, 2012 
V $\varepsilon$

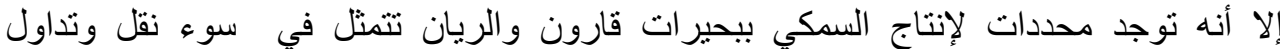

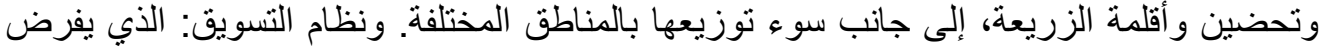

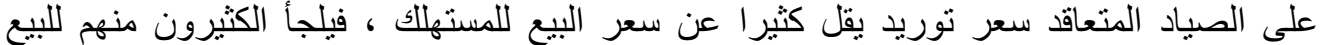

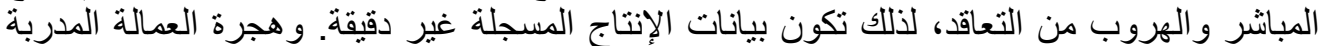

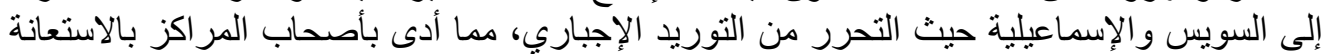

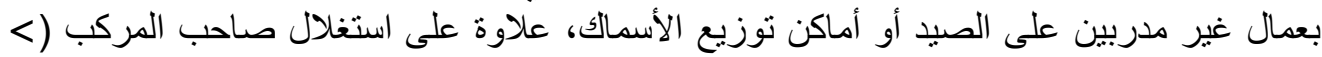

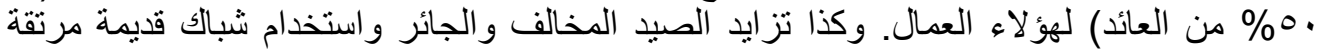

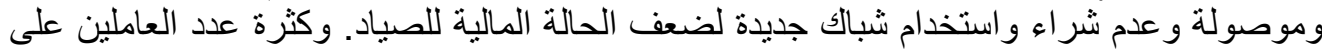

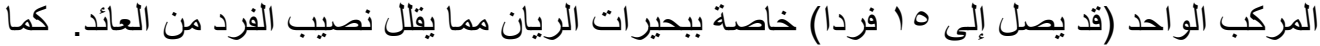

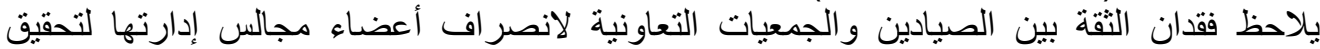

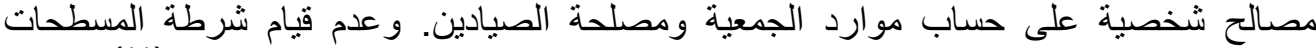

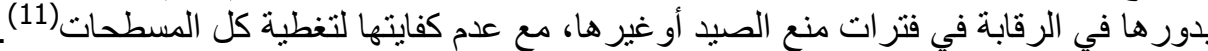

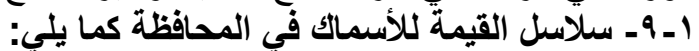

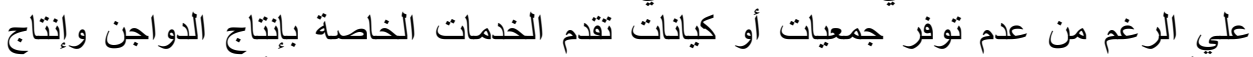

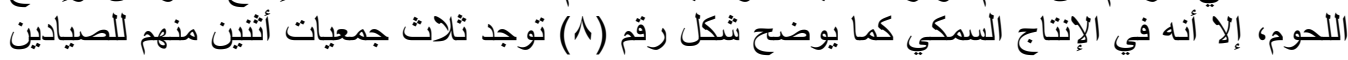

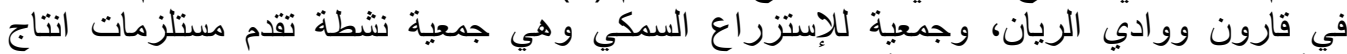

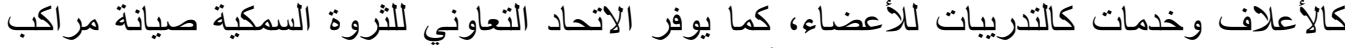

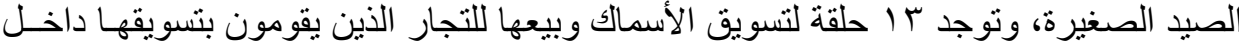
شكل رقم (^) سلسلة القيمة للأسماك في محافظة الفيوم الفاف

\section{Mapping Fish Value Chain}

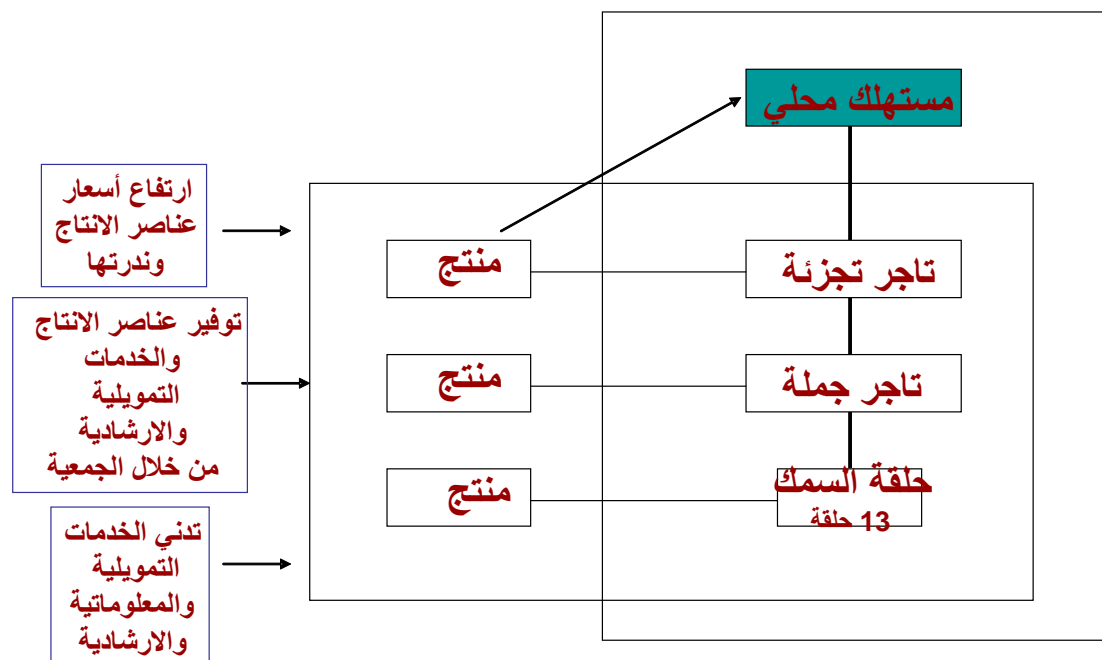

المصدر: تم تصميم الثكل من واقع المقابلات و الزيار ات الميدانية لجميع الفئات داخل سلسلة القيمة

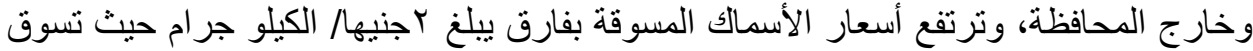

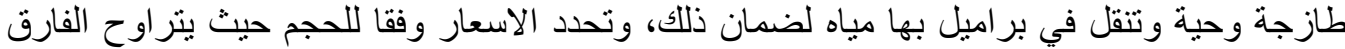

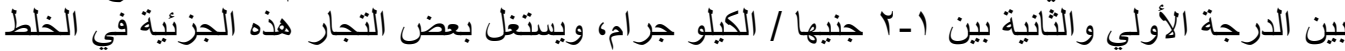

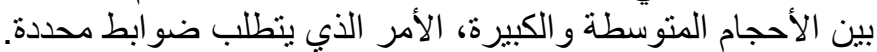

Fayoum J. Agric. Res. \& Dev., Vol. 26, No.2, July, 2012 
Vo

وتعتمد المناطق القريبة من بحيرة قارون علي أعداد وجبات جاهزة من الأسمالك الطازجة،

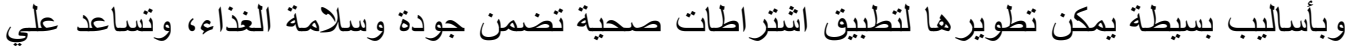

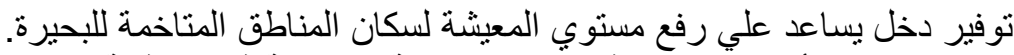

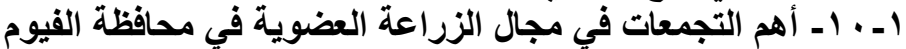

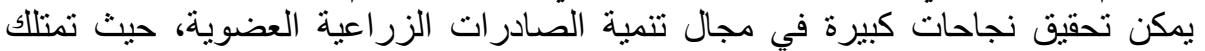

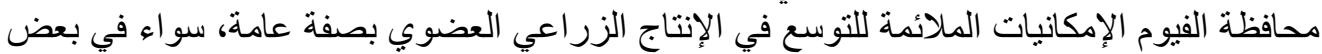

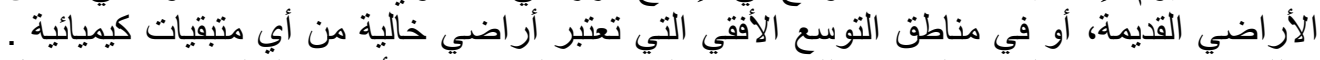

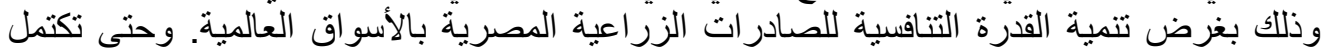

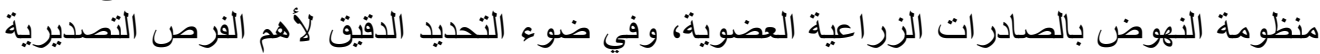

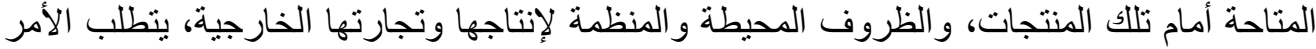

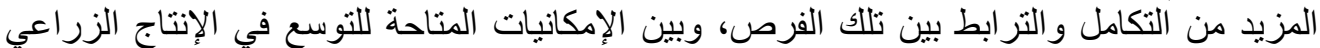

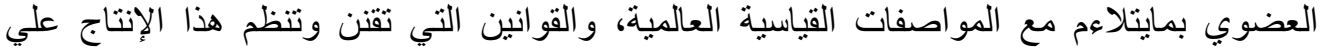

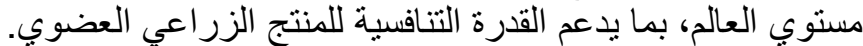

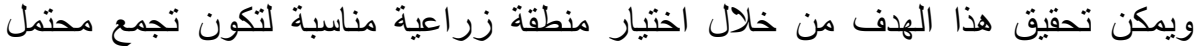
كمرحلة أولية وتجريبية يمكن تكرارها بعد ذللك في مناطق أخري ينشأ بها مركز لتنمية الإنتاج

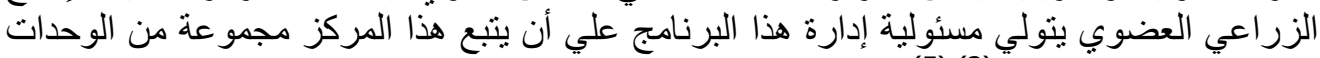

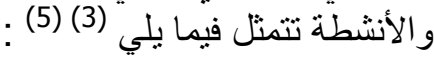

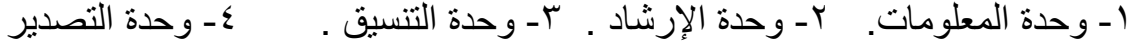

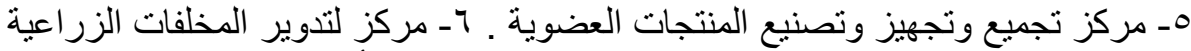

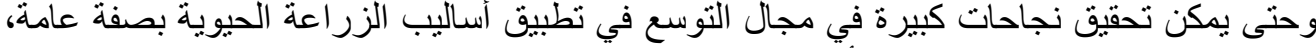
فإنه يجب الاهتمام بمجمو عة قو اعد أو جو انب رئيسية تتمنل فئل فيما يلي:

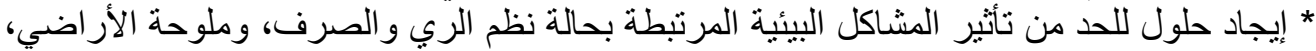
وقد أثبتت بعض الدراسات في مجال استصلاح الأراضي، الدور الإيجابي للأسمدة العضوية في

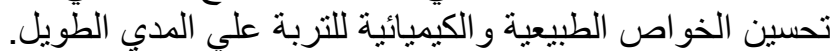

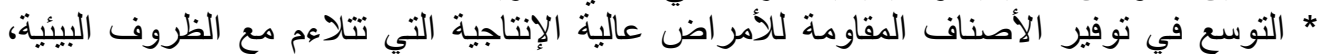

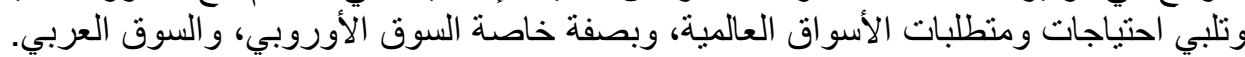

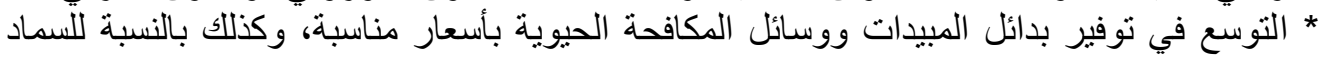

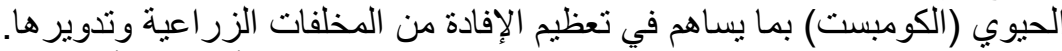

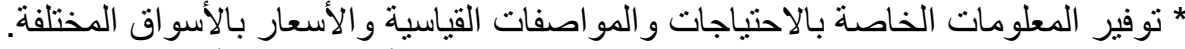

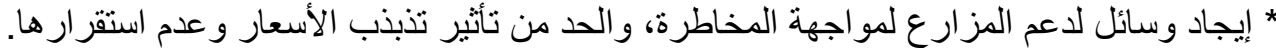
* تشجيع الاستثار ات في مجال الخدمات الزر اعية، وبصفة خاصة معاملات ما بعد الحصاد كالفرز

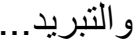
* تنظيم بر امج لتوعية المزارعين بمخاطر واحتباطيات الأمان، و الحدود المثلي للاستخدام، وتوفير آلات الرش التي تدني الفاقد وتحد من الإفر اط في إست استخدام المبيدات. * تنظيم بر امج للتدريب علي أساليب الزر اعة الحيب الحيوية كحزمة متكاملة، وتدريب كوادر من المرشدين و الاستشنار بين المتخصين. * تتظيم التشريعات المقنتة لتداول المبيدات، و الرقابة و السيطرة علي تجارتها، وزيادة الضر ائب عليها للمساهمة في الحد من آثار ها السيئة. * التنسيق بين السياسات البحثية والإرشادية والتنفيذية والراتية الرقابية للحد من الآثار السلبية للمبيدات علي البيئة و المستهلك و الاقتصاد القومي. لئسئ

شكل رقم (9 ) تجمع مقترح للزراعة العضوية في محافظة الفيوم

Fayoum J. Agric. Res. \& Dev., Vol. 26, No.2, July, 2012 


\section{The way to develop Clusters}

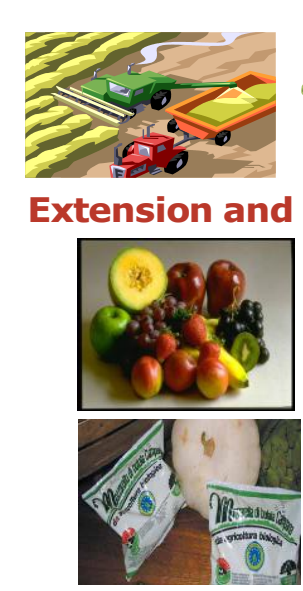

Logistics
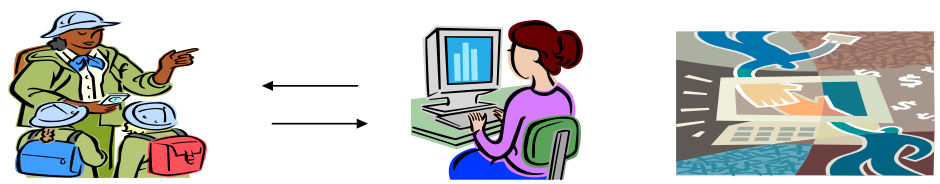

Information and market study

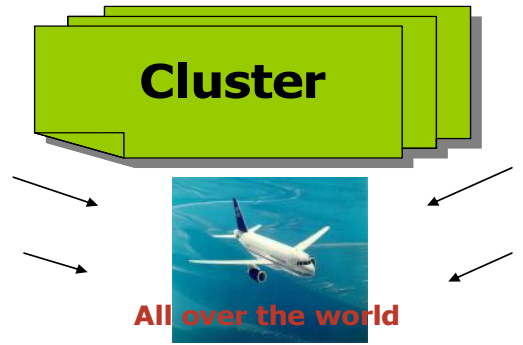

safe and height quality product

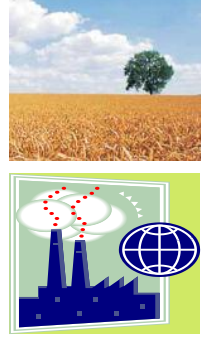

Recycling

كما يوصي بتشجيع التوسع في نطبيق أساليب الزراعة الحيوية علي مستوي محافظة الفيوم

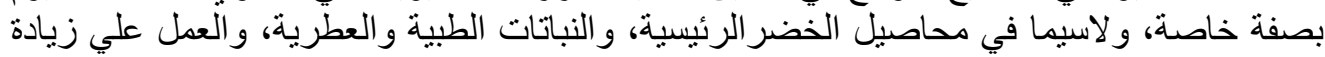

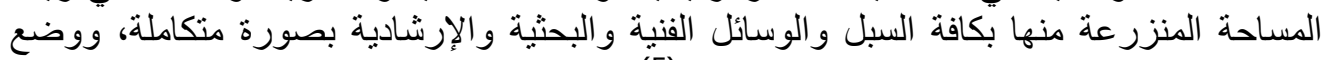

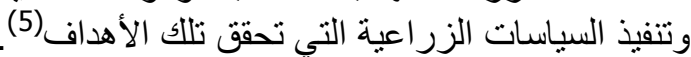

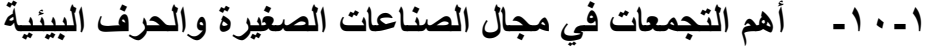

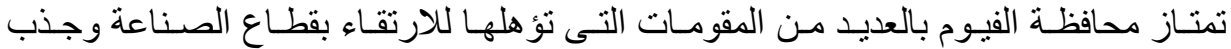

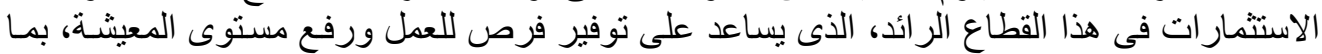
يدفع عجلة التنمية الاقتصادية بالمحافظة، وتتيح المقومات الترات الخاصة بطبيعة وموفع محافظة الفيوم مز ايا

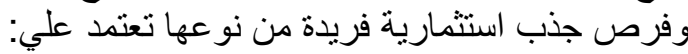

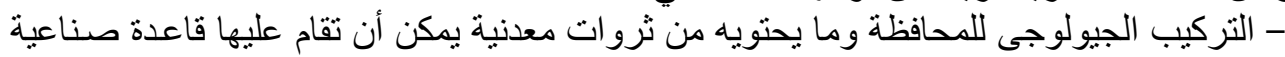
كبيرة .

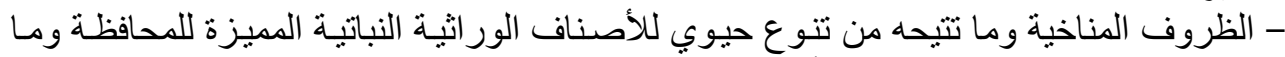

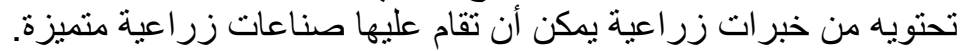

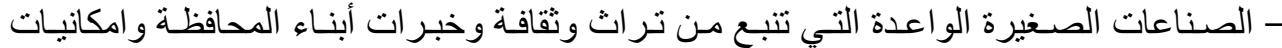

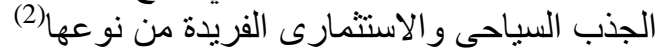

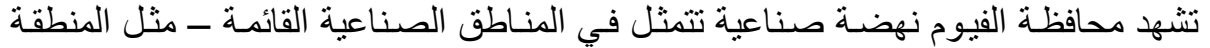

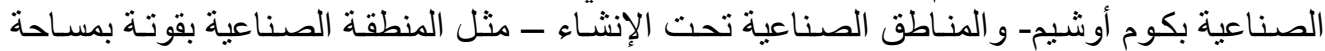

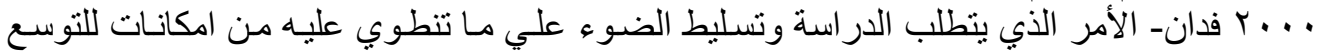

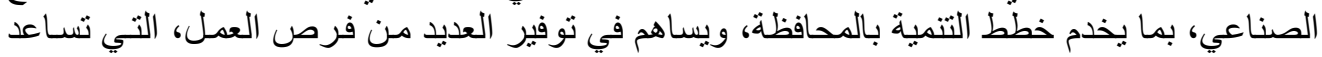

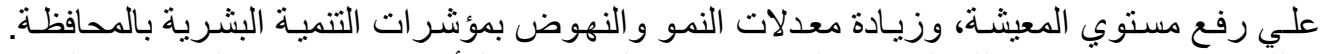

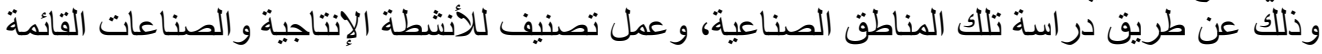

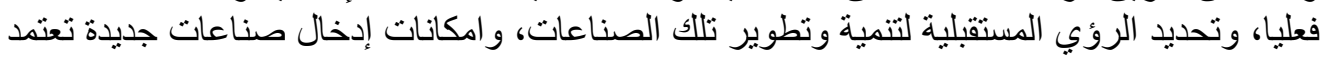

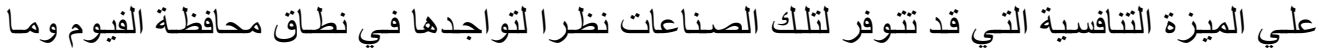

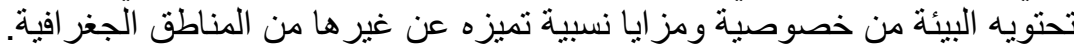

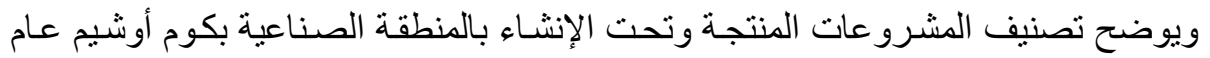

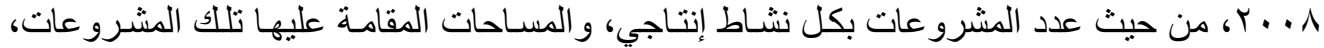

Fayoum J. Agric. Res. \& Dev., Vol. 26, No.2, July, 2012 


\section{VV}

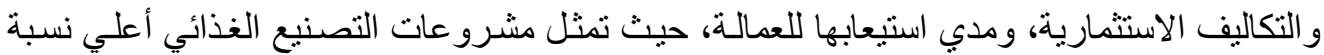

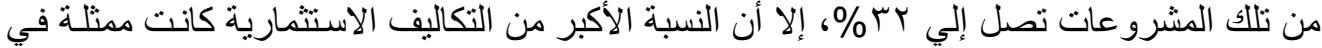

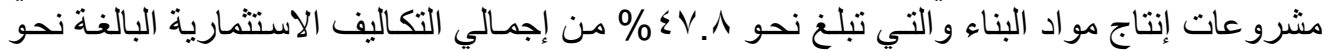

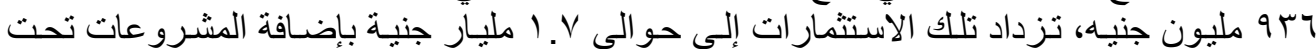

وحتي يمكن تفعيل دور تللك الاستثمار ات لابد من التكامل بين تلك المناطق الصناعية من جهة،

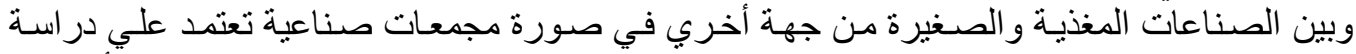

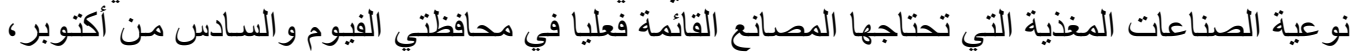

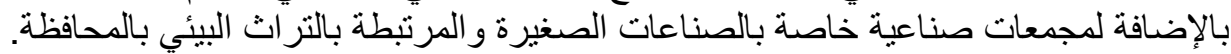

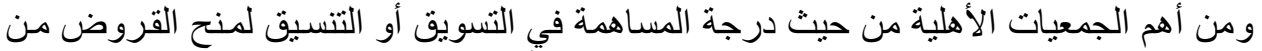

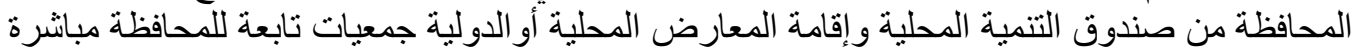

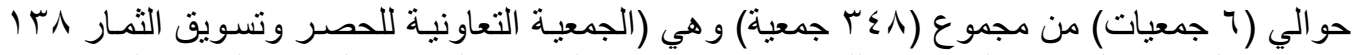

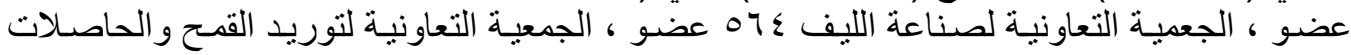

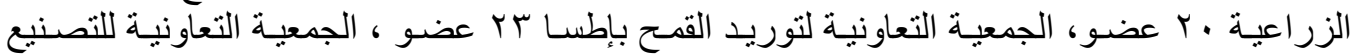

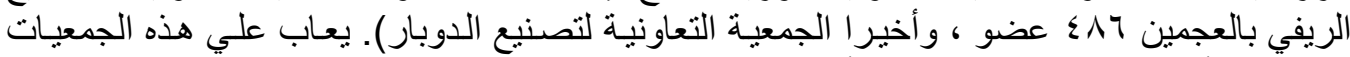

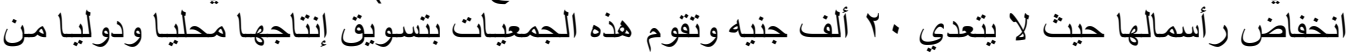

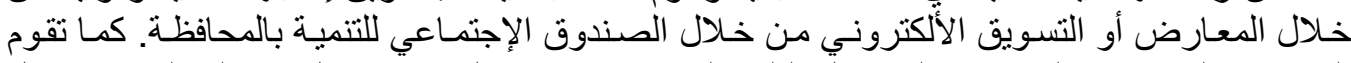

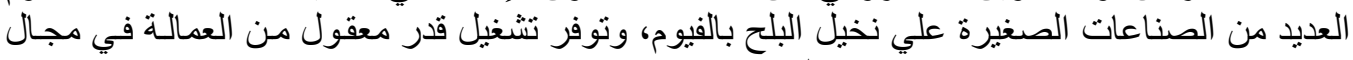
إنتاج و إعداد وتسويق منتجاته، ومن هذه العن الصنات الصناعات:

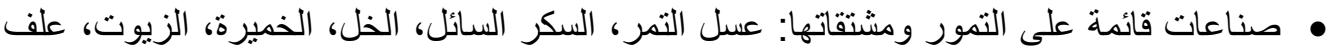

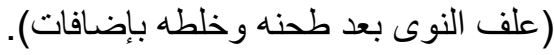

• صناعات قائمة على الخوص (يدوية) : الحصر والأسبتة، والحقائب اليدوية و القبعات و الدكانس و والمقاطف و السلال و غير ها.

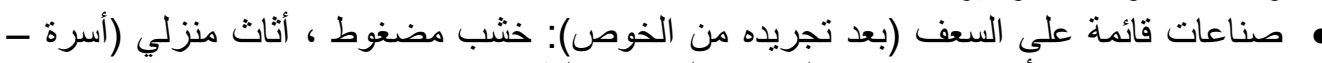

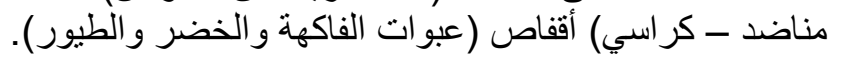

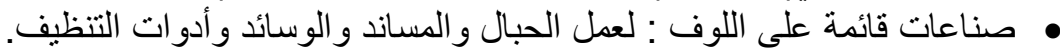

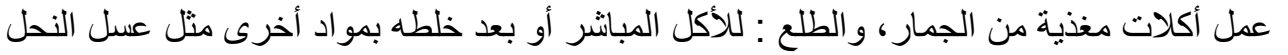

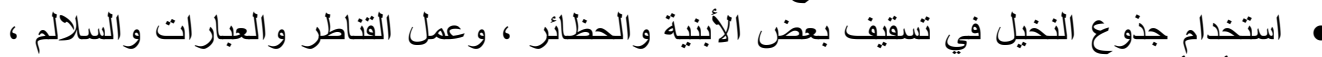

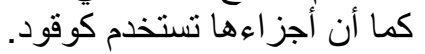

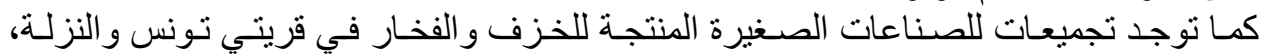

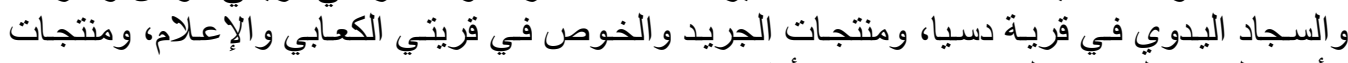

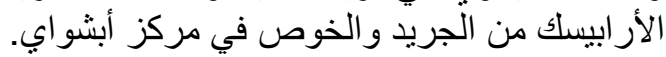
تواجه الصناعات الصغيرة في محافظة الفيوم التعديد من المشكلات و المعوقات الصنات منها ما يتعلق بالتمويل

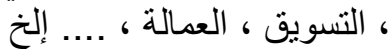

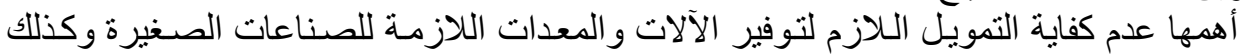

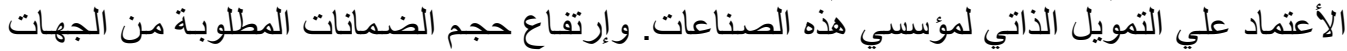

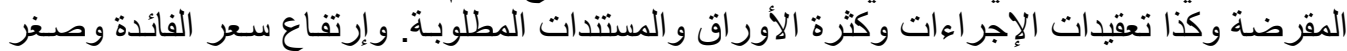

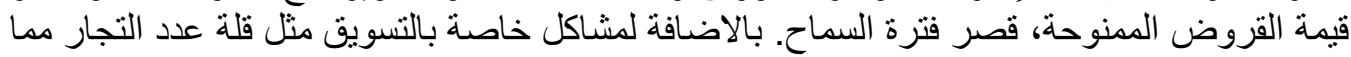

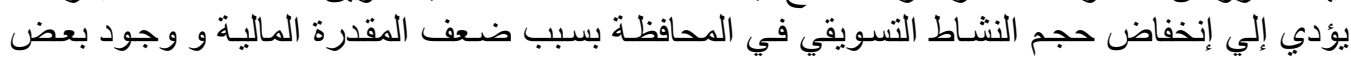

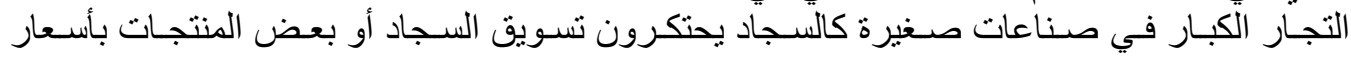

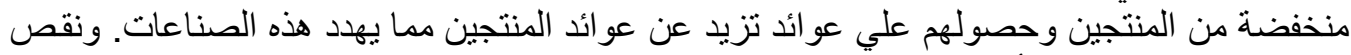

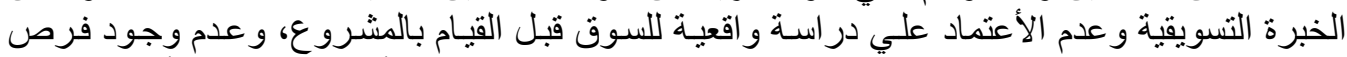

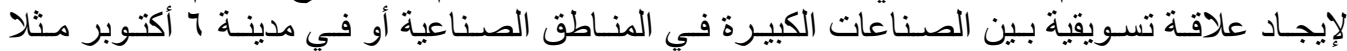
و الصناعات الصغيرة بحيث تكون صناعات مغذية لهات لهات الصنا

Fayoum J. Agric. Res. \& Dev., Vol. 26, No.2, July, 2012 
$\vee \wedge$

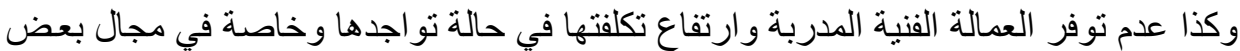

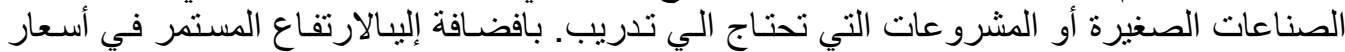

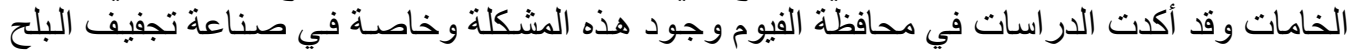

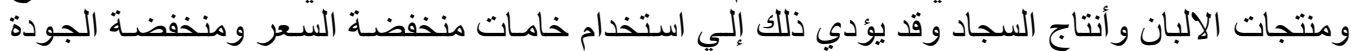

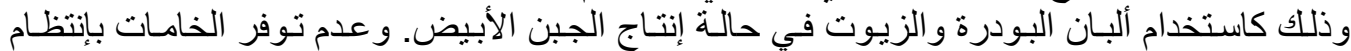

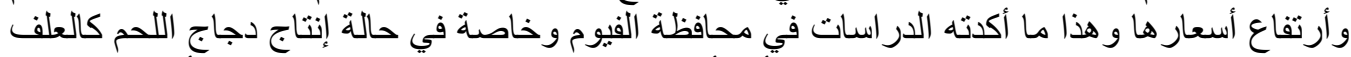

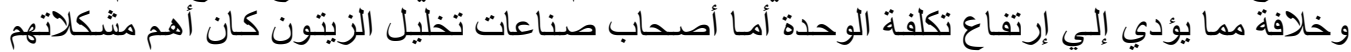

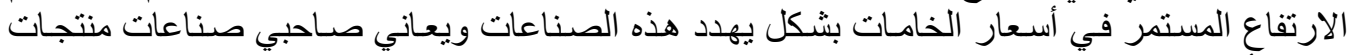
النخيل أيضا من نفس المشكلة.

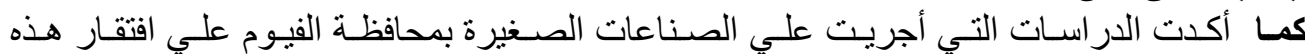

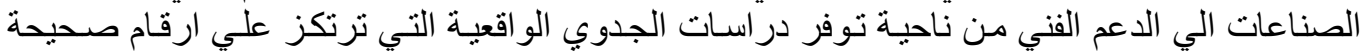

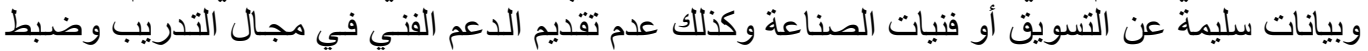

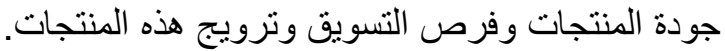

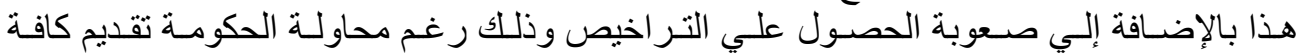

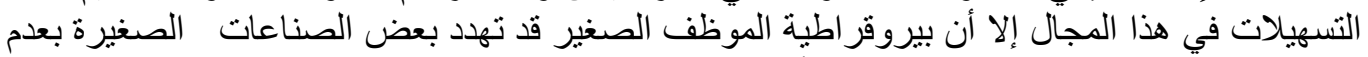

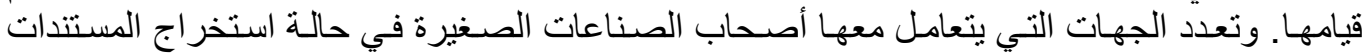

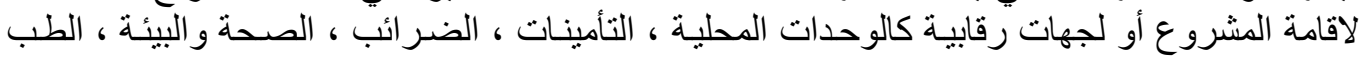

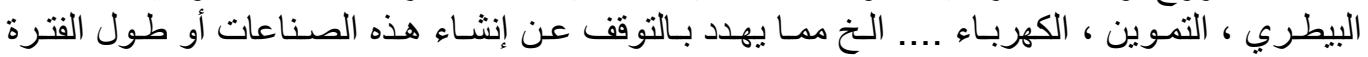

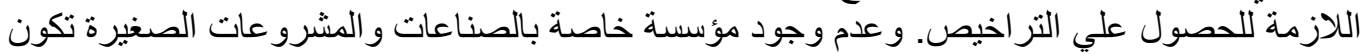

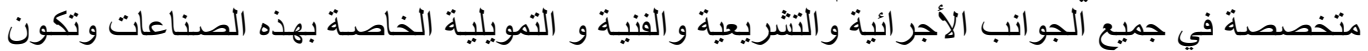

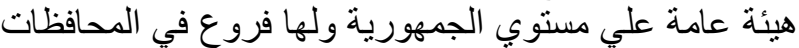

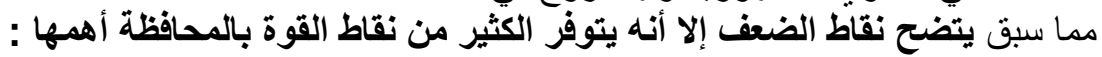

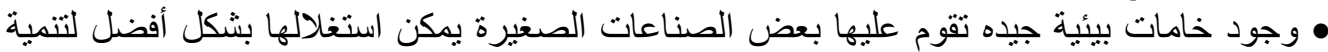
هذا القطاع.

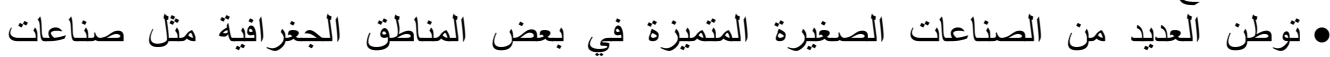

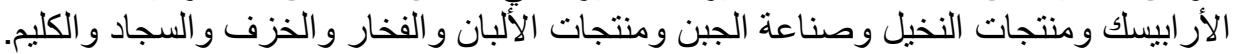

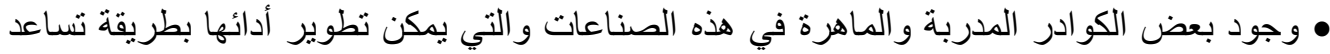
علي تقدم هذه الصناعات. • تمتع محافظة الفيوم بموقع هام علي الخريطة السياحية في مصر وإمكانية استغلال ذللك في ترويج

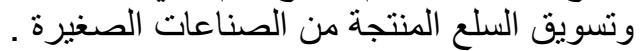
• وجود الإدارة الأقليمية للصندوق الإجتماعي للتنمية يساعد علي رفع عجلة التئة التنمية لقطاع الصناعات

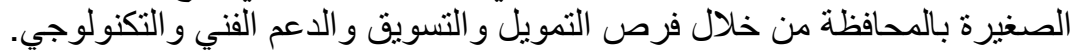

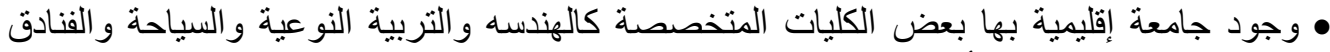

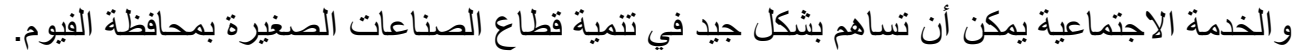

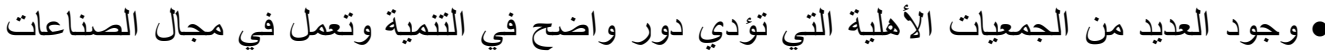

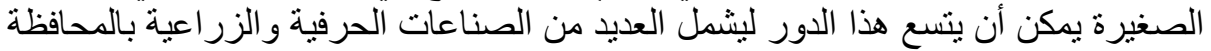

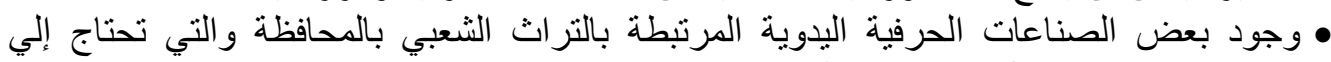
رعاية وتطوير من خلال الامكانيات المتاحة.

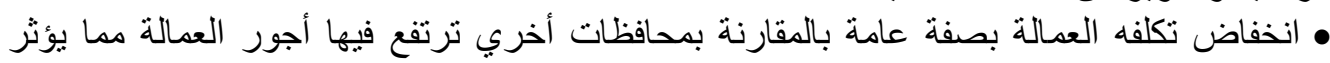
سلبيا علي تكلفة الوحدة للمنتج.

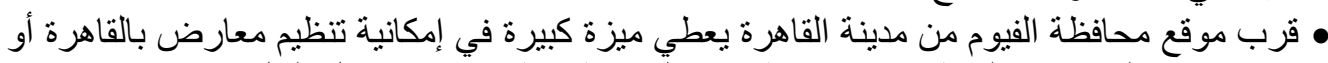

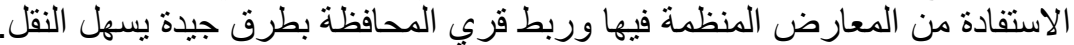

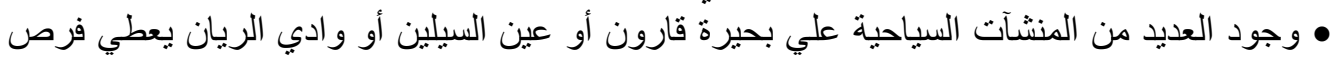
تسويقية ممتازة لبعض الصناعات الصنيرة الصنياحة

Fayoum J. Agric. Res. \& Dev., Vol. 26, No.2, July, 2012 
Vq

• تمتع المحافظة بتركيب محصولي منتوع يتيح الفرصة لتوفير خامات لإقامة صناعات زراعية متمبزه (6) (1)

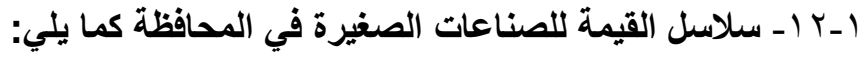

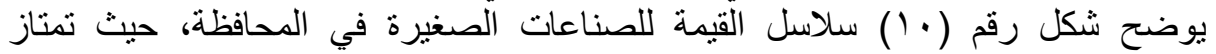

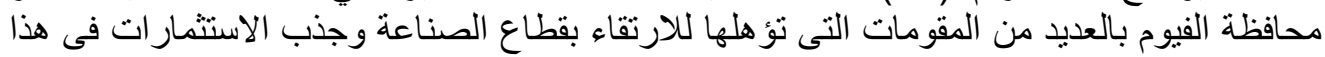
القطاع الرائد، الذى يساعد على توفير فرص للعمل ورفع مستوى المعيشة، بما يدفع عجلة التنمية

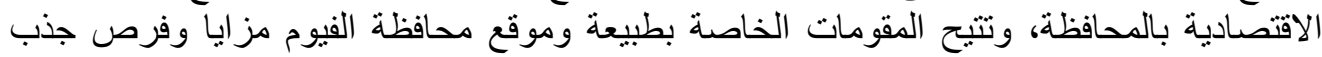

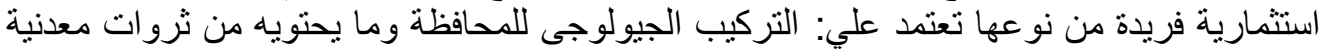

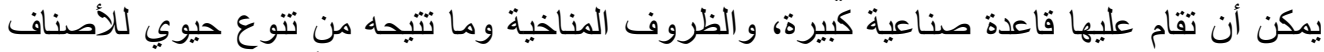

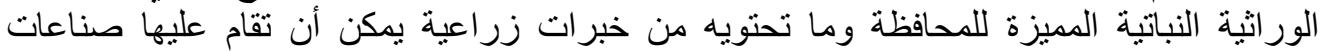

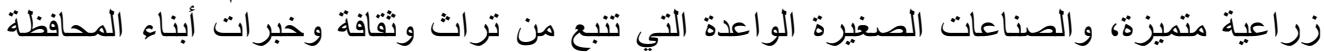

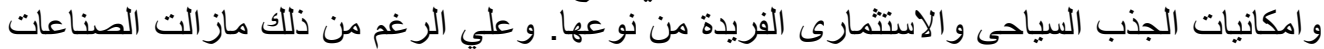

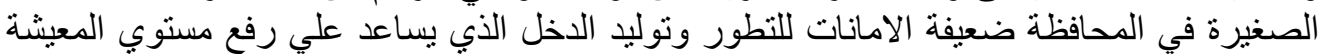

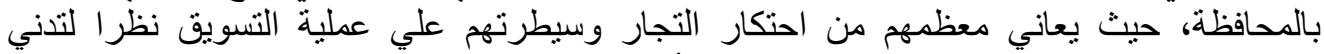

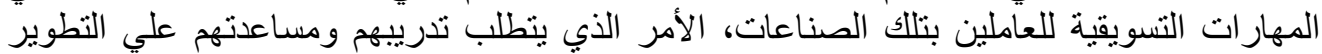

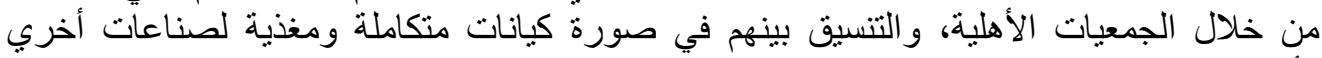

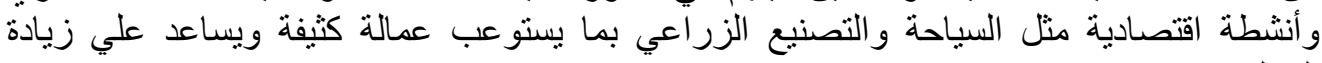

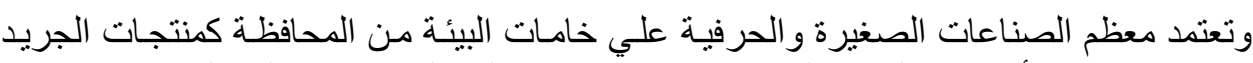

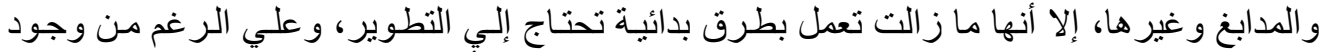

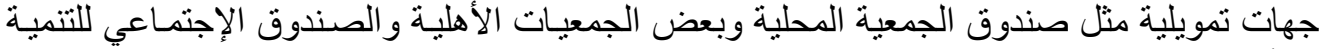

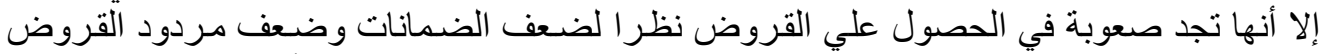

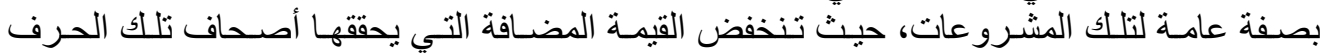
و المشروعات الصغيرة، في حين تصل القيمة المضافة التي يحققها التجار في هذا المجال إلي أضعاف ما بحققه المنتجون.

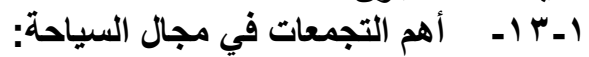

الفيوم و احة ساحرة جذبت أنظار العالم بتر اثها الطبيعي و الجيولوجي والأثري. تستمد مياهها

من نهر النيل عن طريق بحر يوسف، وقد تجمعت العديد من العوامل التي تجعل من الفيوم مكانا

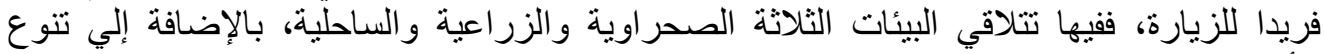

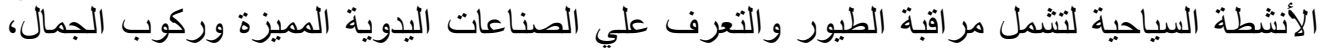

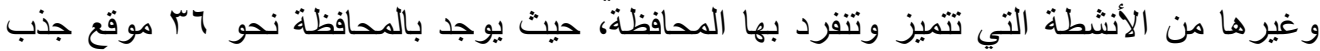

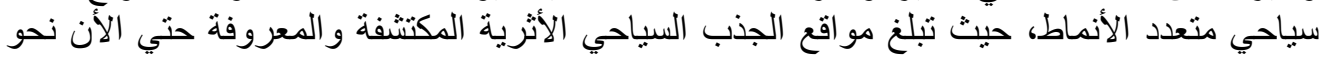

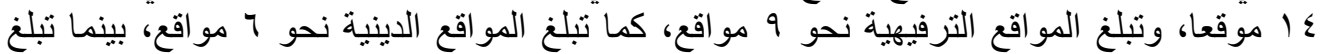

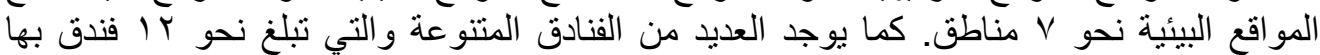

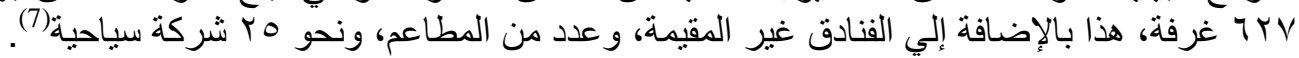

شكل رقم ( • 1) سلسلة القيمة للصناعات الصغيرة في محافظة الفيوم

Fayoum J. Agric. Res. \& Dev., Vol. 26, No.2, July, 2012 
$\wedge$.

\section{Mapping MSE Value Chain}

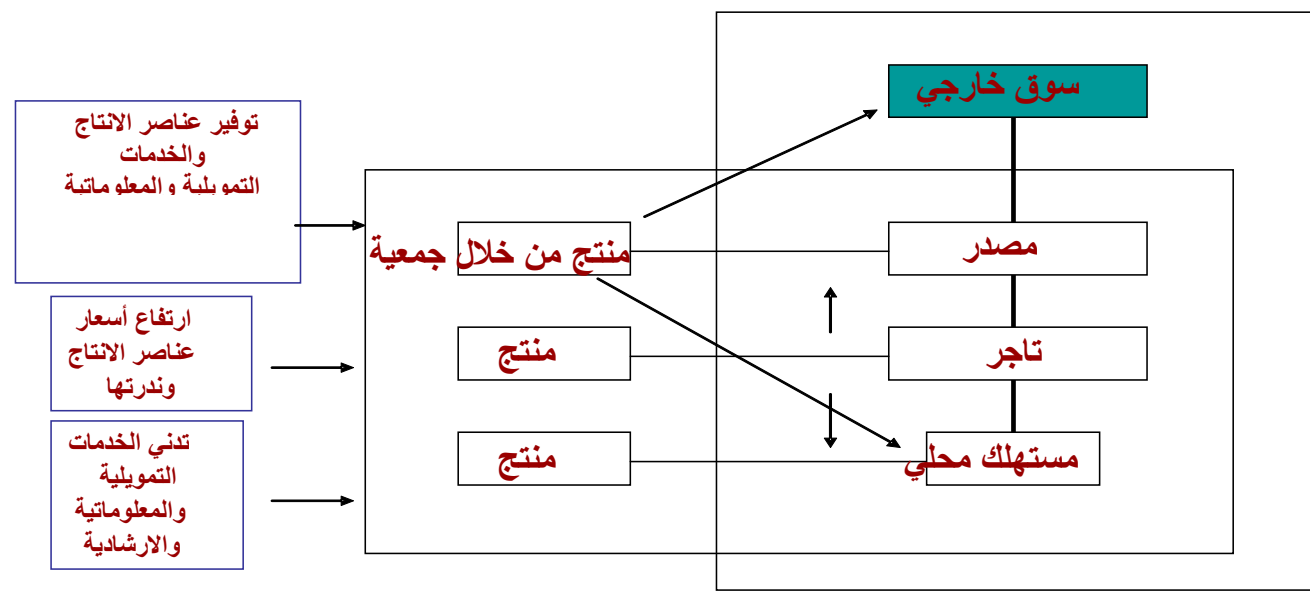

المصدر: تم تصميم الثكل من و اقع المقابلات و الزيار ات الميدانية لجميع الفئات داخل سلسلة القيمة

تتمتع محافظة الفيوم بمجموعة من المقومات السياحية وخصائص الجذب السياحي التي تؤهلها أن

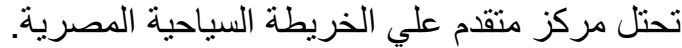

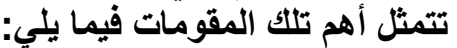

مقومات السياحة الدينية (تحقق ميزة تنافسية ضعيفة بالمقارنة بالقاهرة وسانت كاترين و الأسكندرية و غير ها من مناطق السياحة الدينية).

مقومات السياحة الترفيهية (تحقق ميزة تنافسية ضعيفة بالمقارنة بالمدن الساحلية على البحر الأحمر و البحر المتوسط).

مقومات سياحة المؤتمرات (تحقق ميزة تنافسية ضعيفة بالمقارنة بالمدن الحضرية الكبيرة مثل

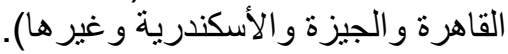
مقومات السياحة البيئية (تحقق ميزة نسبية فى الغالب الأعم قوية بالمقارنة فيزة بمناطق السياحة البيئية الأخرى فى مصر ).

تزايد الطلب العالمى على رحلات السياحة البيئية بمختلف مستوياتها، حيث تتراوح نسبتها من

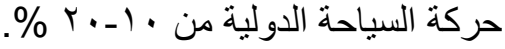
تز ايد الر غبة فى الإنفاق من قبل السياح البيئيين للمحافظة على البه من البيئة. وجود جهات تمويل دولية توفر المبالغ اللازمة والدعم المادى للنهوض فئن بمناطق السياحة البيئية

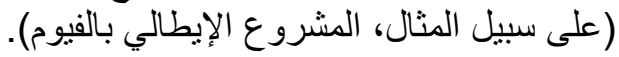

توقع زيادة نسبة المناطق المحمية بالفيوم كمحميات طبيعية وتراثية الإبية عالمى، مثل منطقة جبل قطر انى و الغابة المتحجرة. و غير ذلك من عناصر أخرى تعظم تجربة السياحة البيئية بالفيوم.

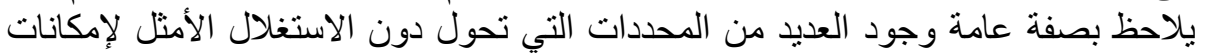

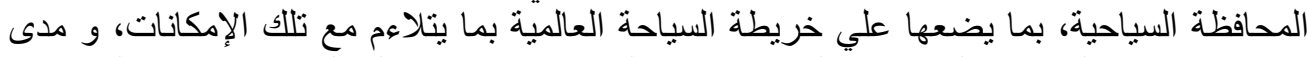

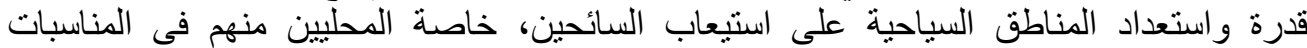
و الأعياد نجد أن مناطق السياحة بمختلف أنو اعها فى الفيوم (الفرعونية_اليونانية و الرومانبة_القبطيةــ الإسلامية) غير مجهزة فى معظمها بأسلوب يناسب حركة السياحة الوافدة إلى المحافظة المافة، ووفقاً

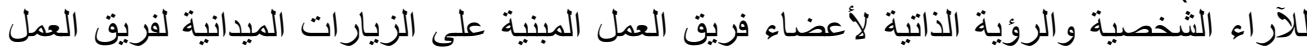

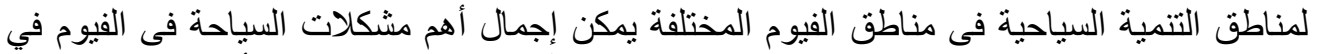

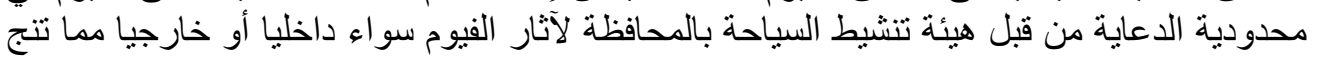

Fayoum J. Agric. Res. \& Dev., Vol. 26, No.2, July, 2012 
A)

عنه عدم معرفة منظمى الرحلات بهذه الآثار. و ومدودية وسائل النقل المتاحة في المحافظة للوصول

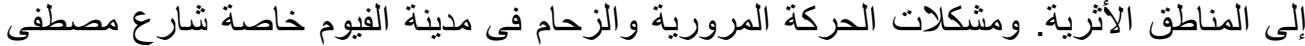

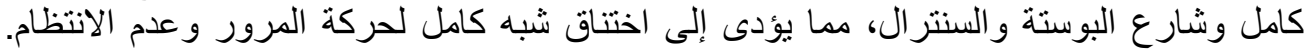

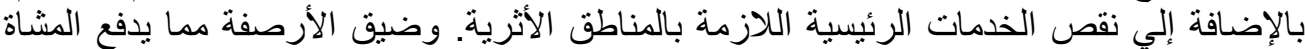

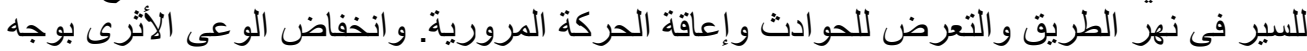

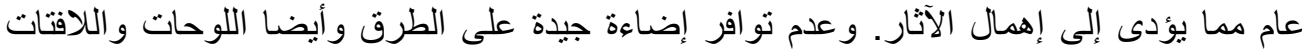

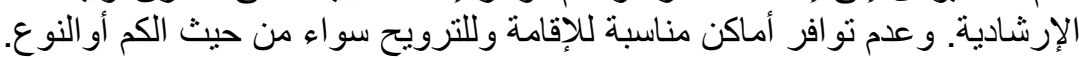

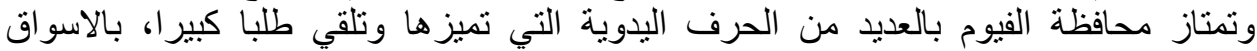
العالمية، كما يتم تسويقها في المناطق السيالية السية محليا أهمها:

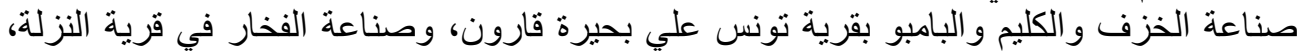

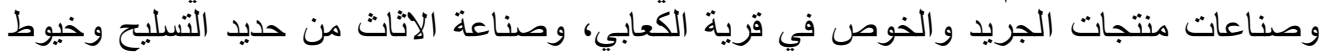
الكتان في أبوكسا، ومن الجريد في العجميين.

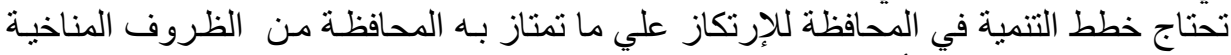

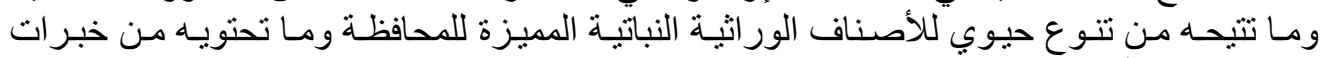

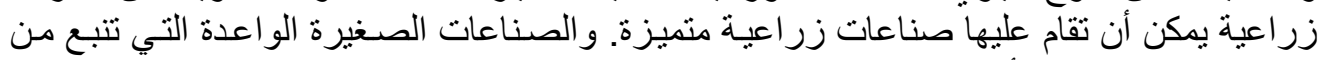

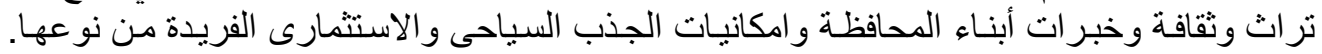

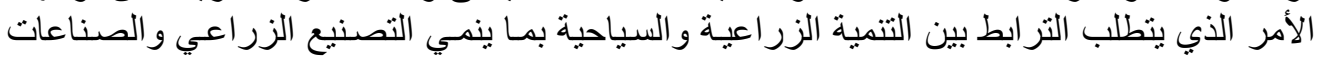
اليدوية الرتبطة بتر اث المحافظة بما يساعد علي النهوض بمسنوي المعيشة.

1 ـ ا ــ سلاسل القيمة للسياحة في المحافظة كما يلي:

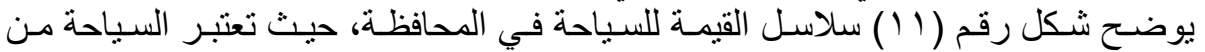

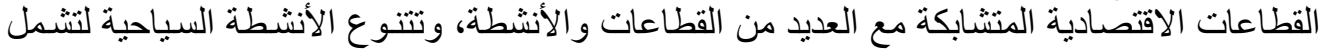

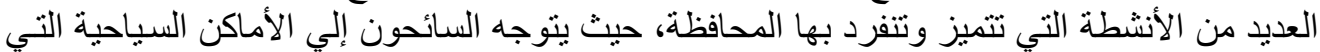

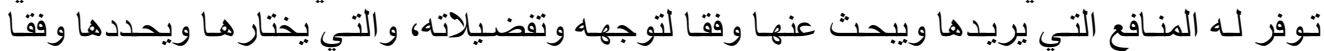

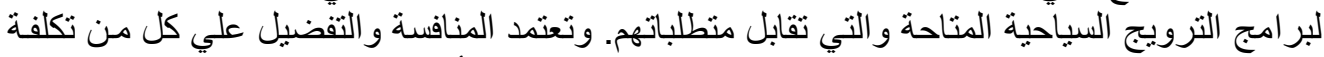

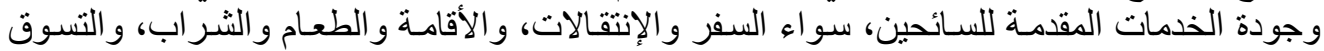

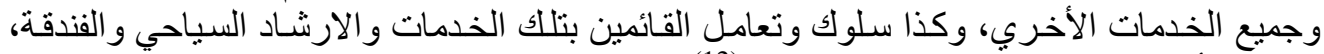

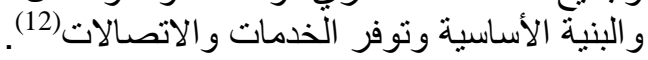

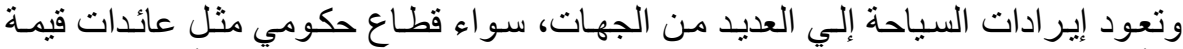

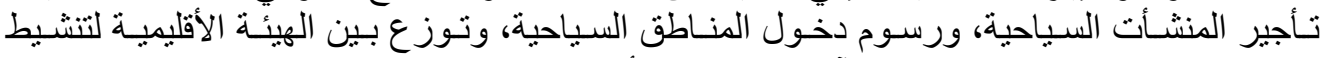

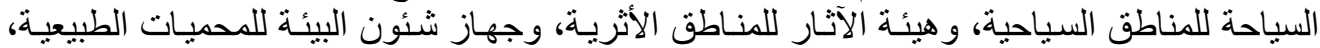

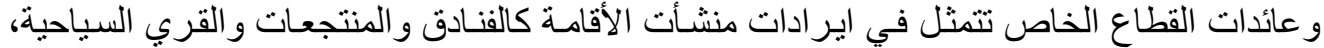

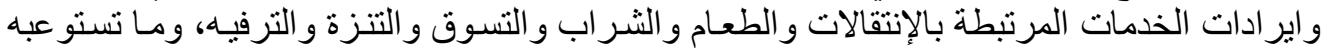

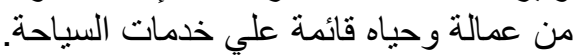

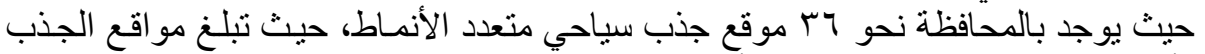

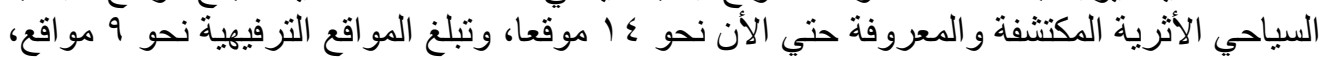

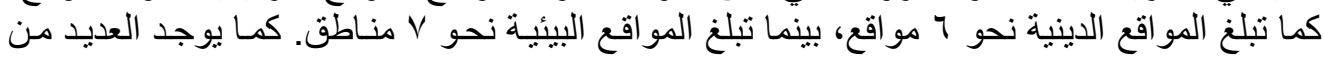

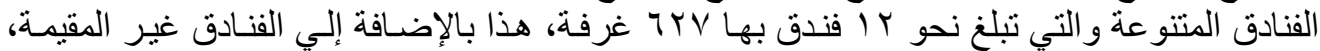

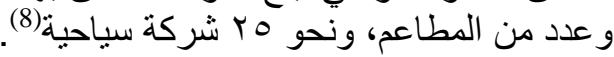

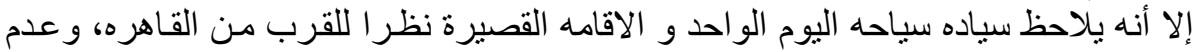

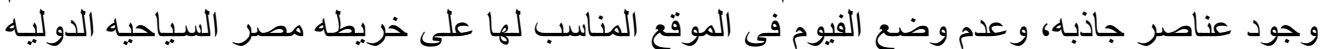

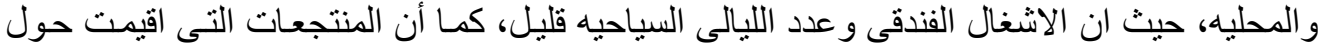

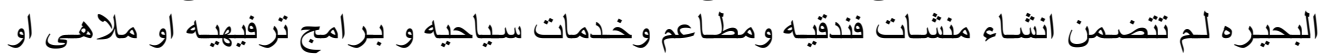
رحلات منظمه لرو اد المناطق السياحيه بالفيوم.

Fayoum J. Agric. Res. \& Dev., Vol. 26, No.2, July, 2012 


\section{Ar}

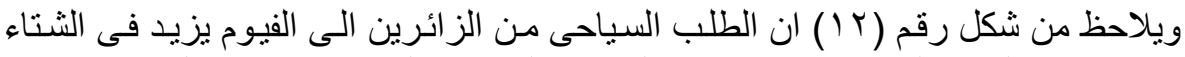

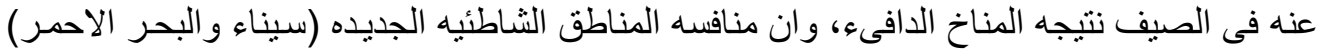

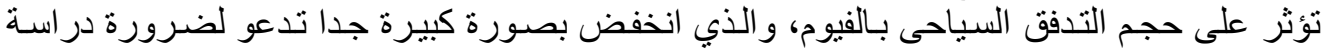

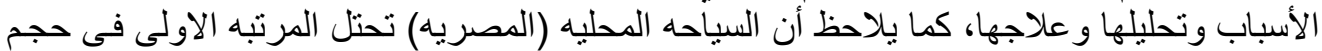

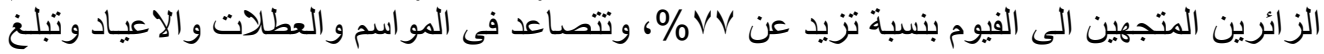

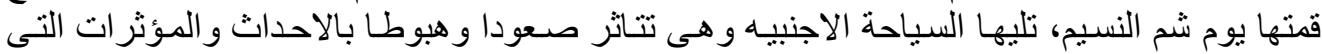

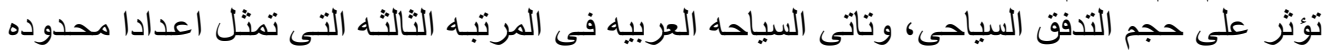

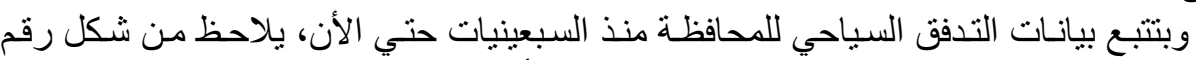

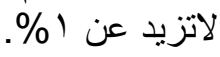

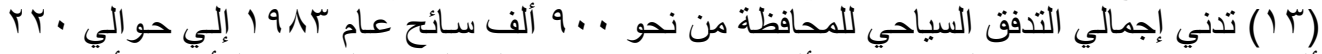

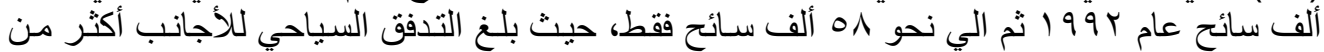

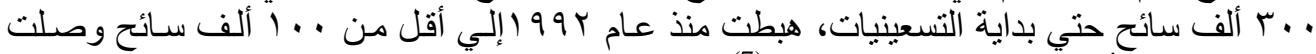

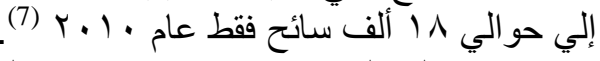

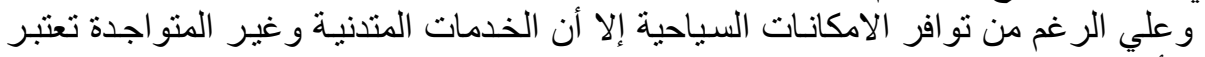

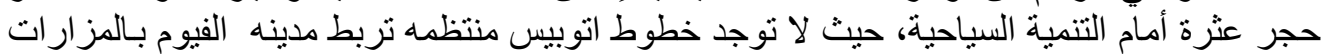

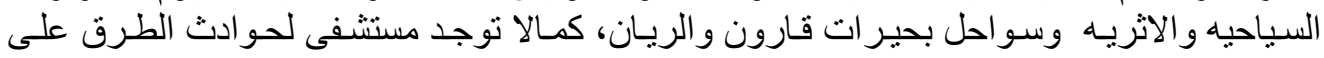

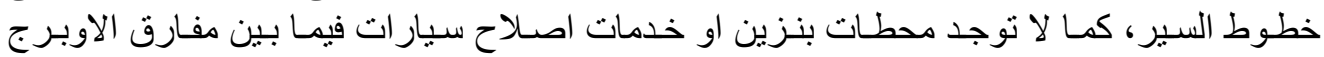

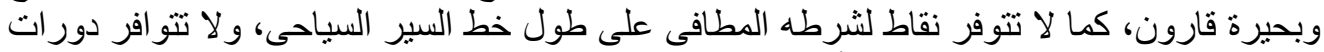

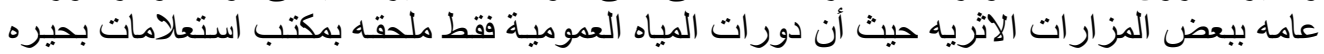

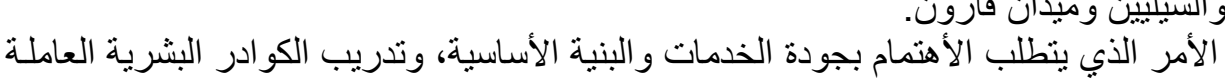
قارون و السيليين وميدان قارون.

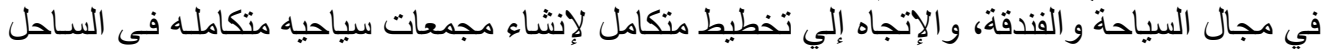

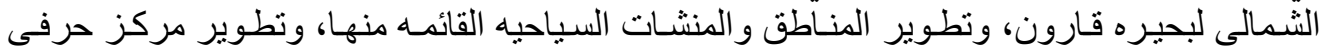

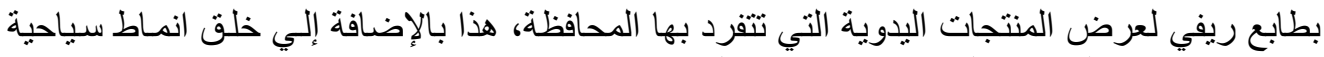

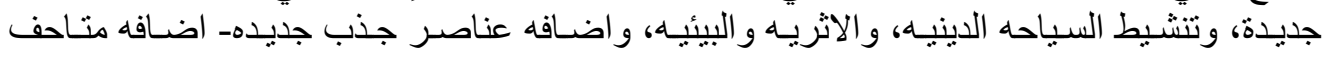

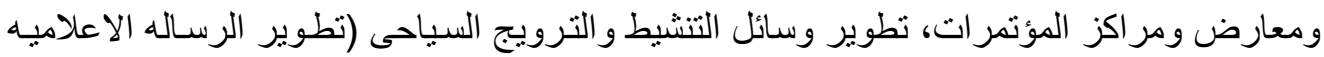

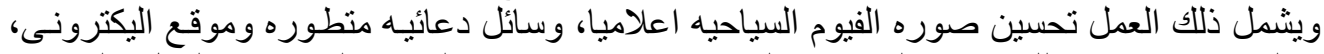

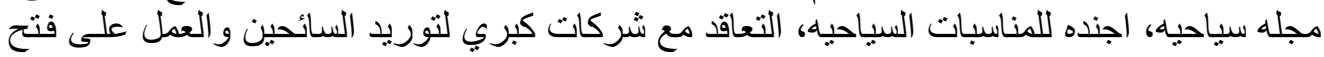

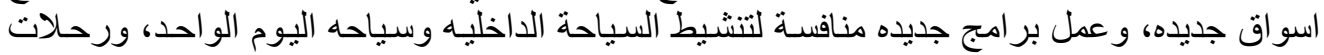

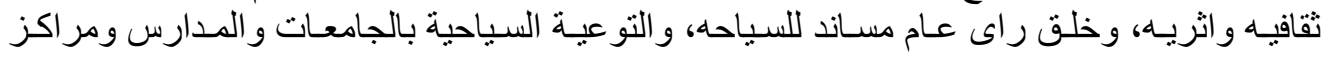

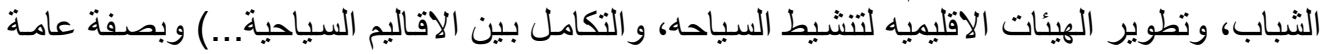

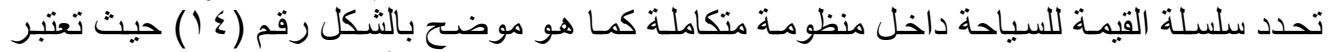

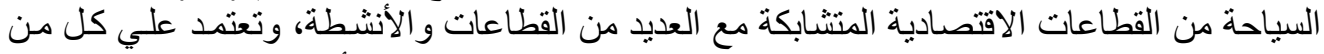

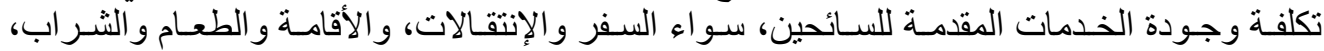

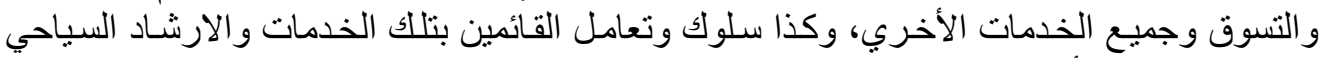

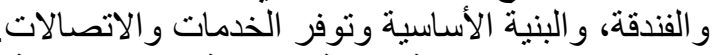

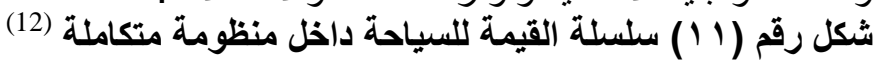

Fayoum J. Agric. Res. \& Dev., Vol. 26, No.2, July, 2012 
$\Lambda r$

The Business Operation

Local Linkage

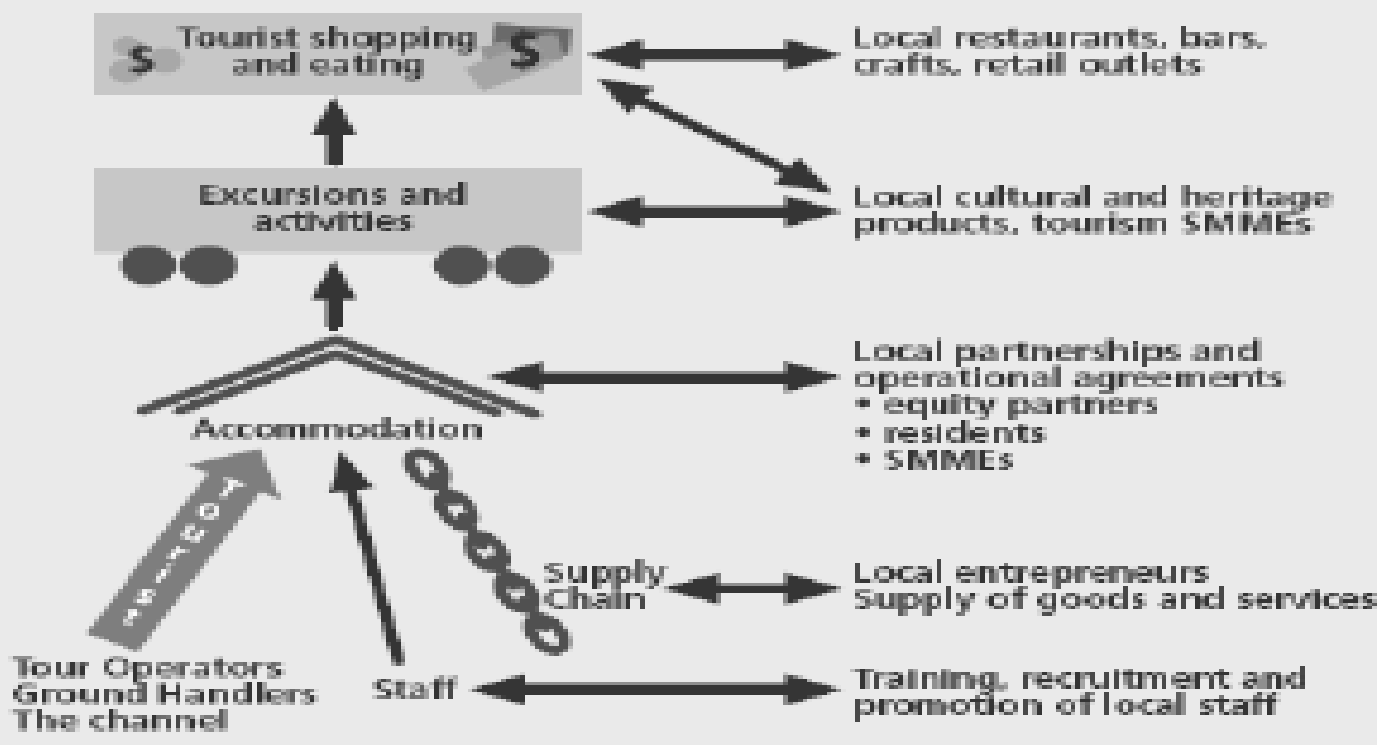

Source: The Gambian Tourist Value Chain and Prospects for Pro-Poor

Tourism Jonathan Mitchell and Jojoh Faal, Overseas Development Institute, March 2008.

شكل رقم (Y I ) التدفق السياحي لمحافظة الفيوم خلال شهور السنة

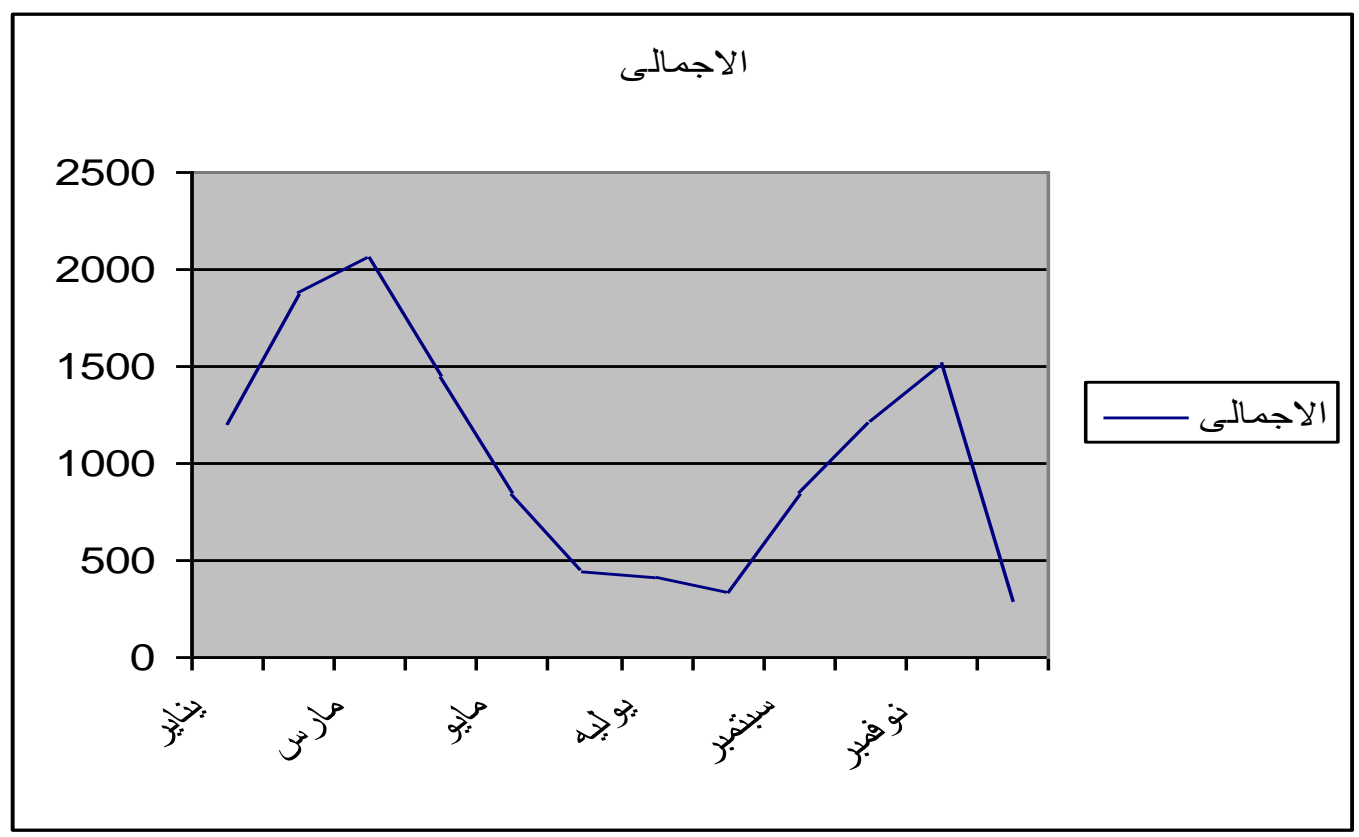

المصدر: احصاءات الهيئة الاقليميه لتنشيط السياحة بالفيوم

Fayoum J. Agric. Res. \& Dev., Vol. 26, No.2, July, 2012 


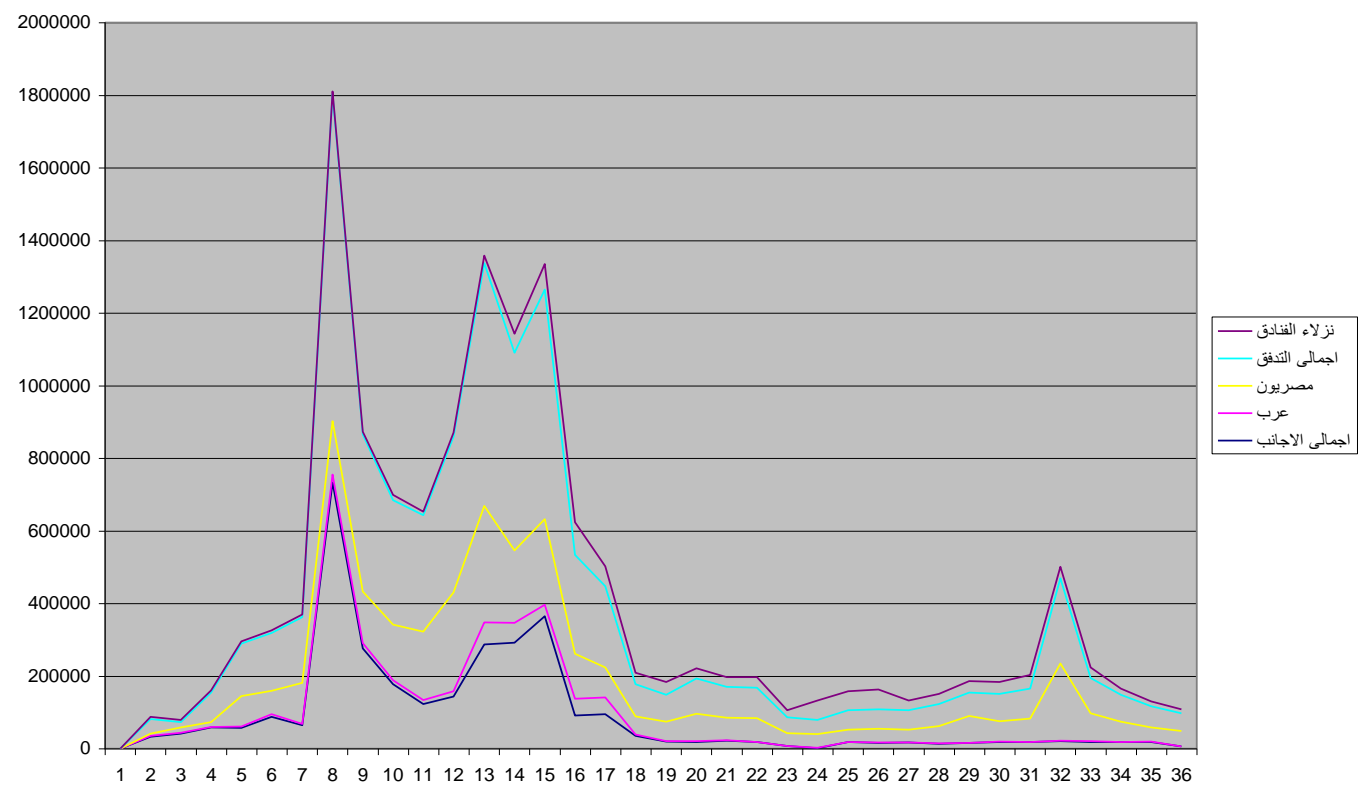

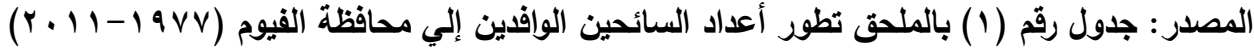

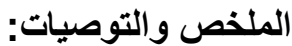

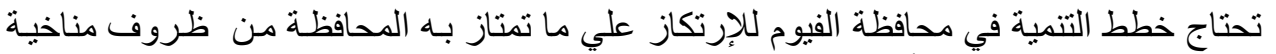

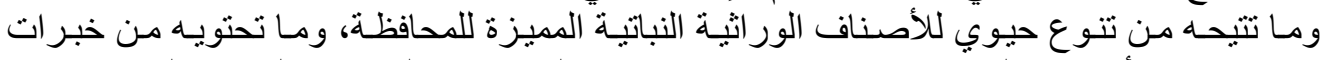

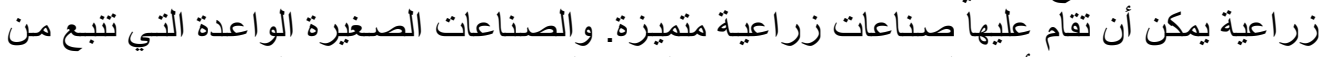

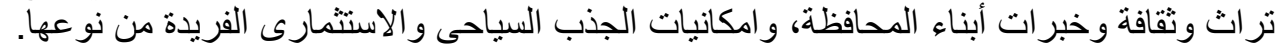

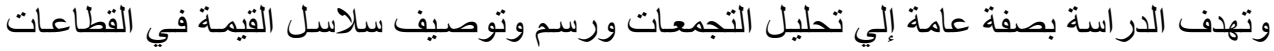

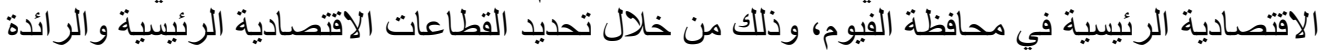

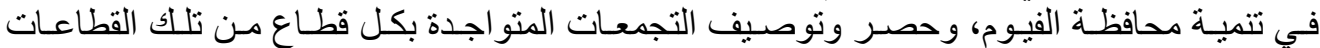

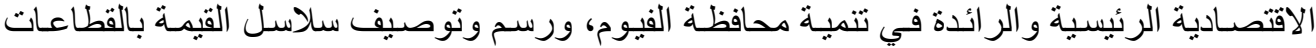

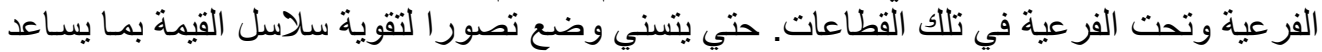
علي رفع مستوي المعيشة بالمحافظة.

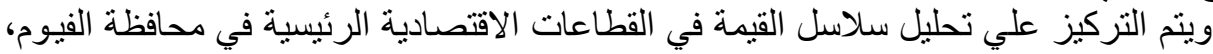

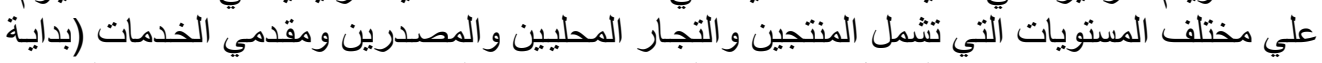

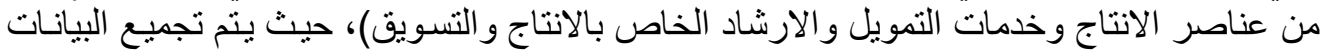

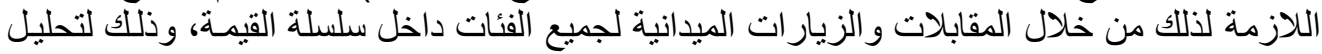

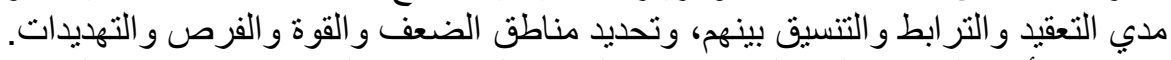

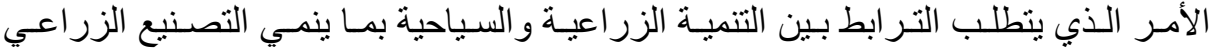

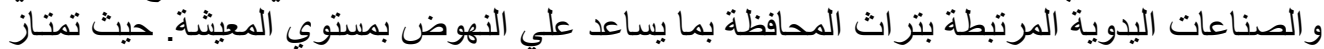

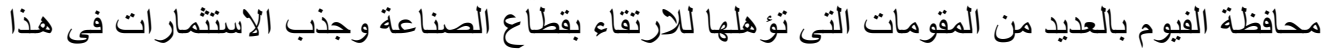

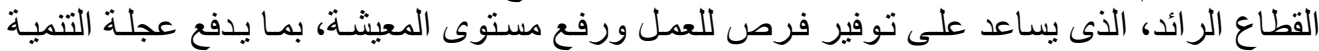

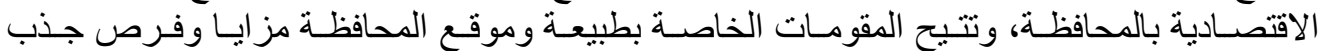
استثمارية فريدة من نوعها.

Fayoum J. Agric. Res. \& Dev., Vol. 26, No.2, July, 2012 
^०

وحتي يمكن تفعيل دور تلك الاستثمار ات لابد من التكامل بين تلك المناطق الكئ الصناعية من

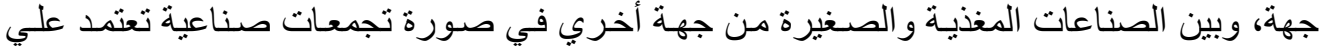

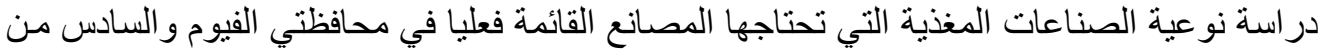

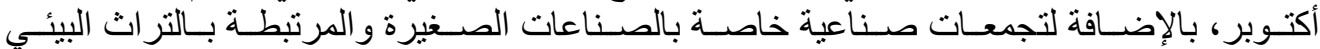

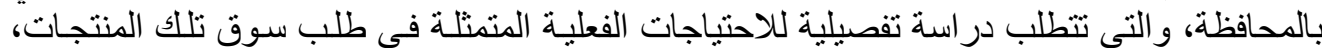

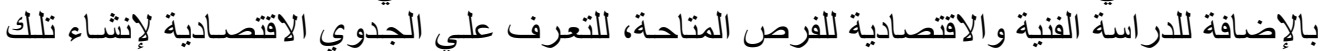

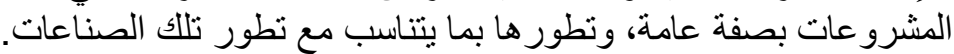

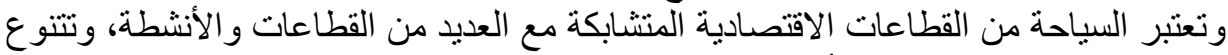

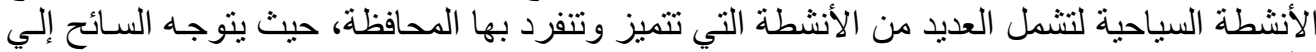

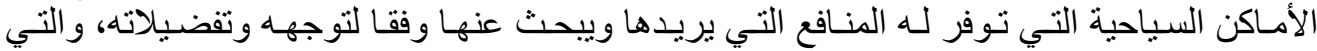

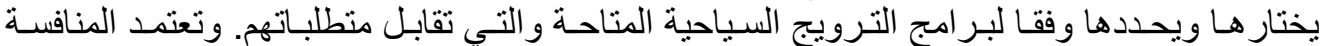

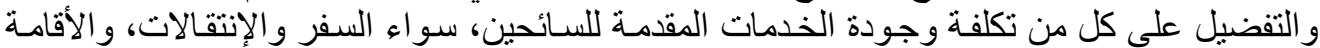

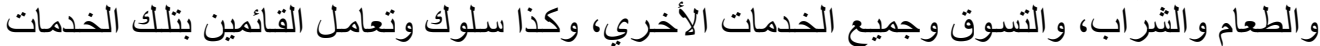

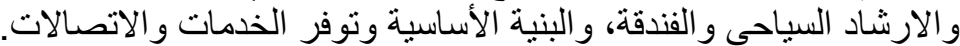

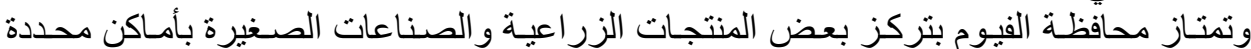

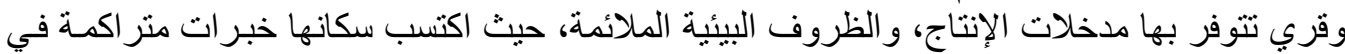

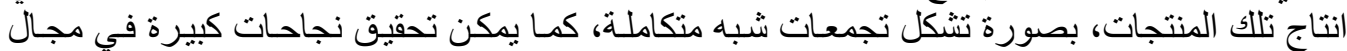

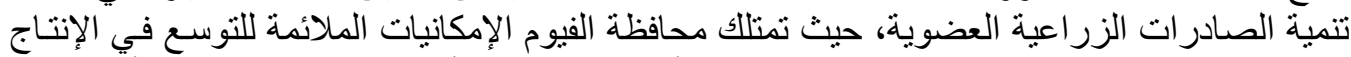

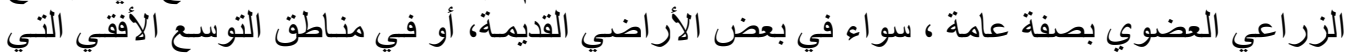

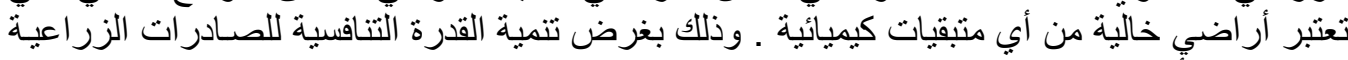

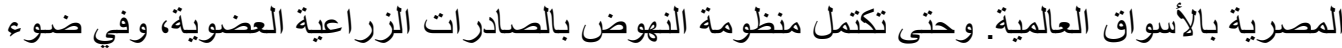

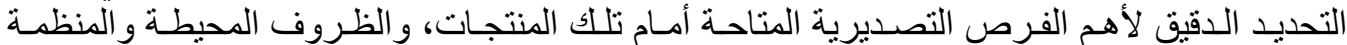

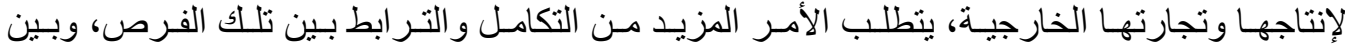

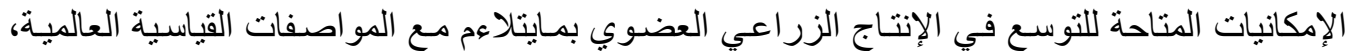

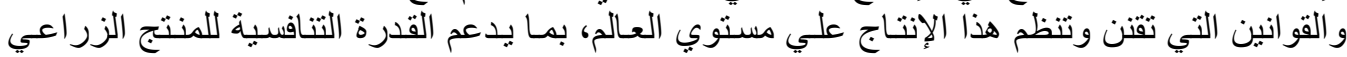

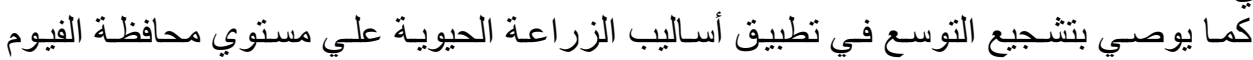

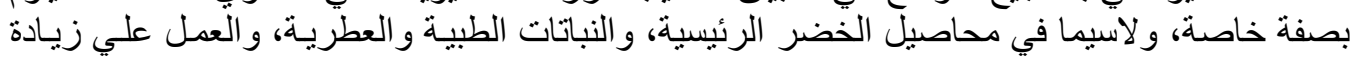

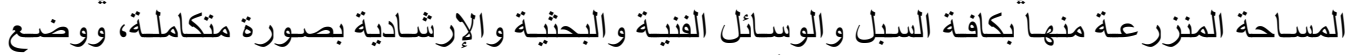
وتنفيذ السياسات الزر اعية التي تحقق تللك الأهداف.

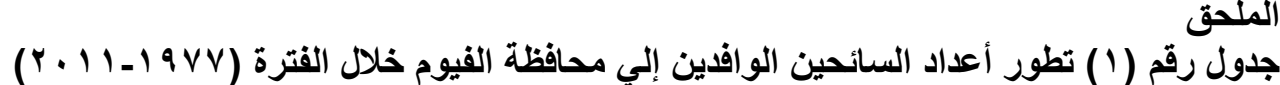

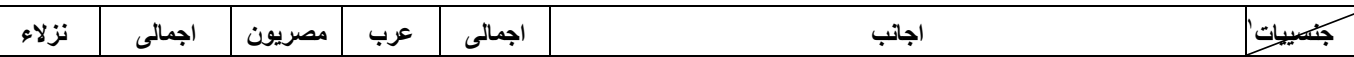

Fayoum J. Agric. Res. \& Dev., Vol. 26, No.2, July, 2012 
$\Lambda$ ง

\begin{tabular}{|c|c|c|c|c|c|c|c|c|c|c|c|c|}
\hline الفنادق & التدفق & & & الاجاتب & جنسيات & اسر ائيليون & | ايطاليون & انجليز & | امريكيون & فرنسيون & المان & \\
\hline 6000 & 40961 & 5799 & 2486 & 32682 & 1526 & 000 & 16341 & 1888 & 1107 & 4340 & 3844 & 1977 \\
\hline 6000 & 14724 & 14779 & 2899 & 40846 & 1626 & 000 & 20423 & 2495 & 3116 & 2419 & 5176 & 1978 \\
\hline 6000 & 81934 & 13009 & 1682 & 58147 & 2688 & 000 & 29075 & 2114 & 4445 & 5109 & 9716 & 1979 \\
\hline 6000 & 144703 & 84046 & 3282 & 57375 & 10496 & 333 & 0000 & 2975 & 4063 & 12394 & 19114 & 1980 \\
\hline 6513 & 159377 & 65153 & 6832 & 87492 & 37041 & 1181 & 000 & 9005 & 6195 & 15788 & 18182 & 1981 \\
\hline 6659 & 181286 & 113513 & 3797 & 63976 & 27053 & 1313 & 000 & 3937 & 6361 & 9788 & 15534 & 1982 \\
\hline 6587 & 901089 & 147635 & 20718 & 733736 & 87202 & 501 & 3277 & 18145 & 34687 & 40259 & 48565 & 1983 \\
\hline 7540 & 432556 & 142248 & 14372 & 275936 & 122573 & 779 & 4488 & 25632 & 23780 & 46288 & 12396 & 1984 \\
\hline 14252 & 342170 & 153550 & 10714 & 177906 & 67807 & 400 & 21324 & 13926 & 19718 & 15548 & 39183 & 1985 \\
\hline 9408 & 321732 & 188295 & 11211 & 122226 & 47888 & 1093 & 7878 & 13223 & 3506 & 17773 & 30866 & 1986 \\
\hline 10512 & 429571 & 273035 & 14682 & 142864 & 51798 & 2716 & 11778 & 19598 & 5038 & 23892 & 27044 & 1987 \\
\hline 20105 & 668932 & 321737 & 59773 & 287422 & 97205 & 3113 & 385.6 & 51697 & 4958 & 53535 & 40408 & 1988 \\
\hline 51817 & 545345 & 198512 & 55277 & 291556 & 105814 & 1282 & 24298 & 54469 & 6054 & & 45301 & 1989 \\
\hline 70199 & 632265 & & & & & & & & 12136 & & 53114 & 1990 \\
\hline 90656 & 271581 & 123758 & 47027 & 90802 & 60782 & 1382 & 4761 & 3648 & 4108 & 5653 & 9868 & 1991 \\
\hline 54560 & 223874 & 82270 & 47242 & 94362 & 55916 & 1197 & 3708 & 4104 & 5052 & 11031 & 13354 & 1992 \\
\hline 31781 & 88474 & 49527 & 4202 & 34745 & 993 & 174 & 812 & 929 & 1621 & 3760 & 7456 & 1993 \\
\hline 34986 & 74118 & 52878 & 1890 & 19350 & 6046 & 599 & 440 & 526 & 1103 & 817 & 3819 & 1994 \\
\hline 28098 & 96505 & 75703 & 2353 & 18449 & 9978 & 1144 & 573 & 569 & 1420 & 785 & 3980 & 1995 \\
\hline 26434 & 85147 & & & & & & & 555 & & & 5906 & 1996 \\
\hline 29092 & 84088 & 65843 & 399 & 17846 & 8025 & 1290 & 1157 & 527 & 959 & 111 & 4777 & 1997 \\
\hline 19488 & 42977 & 35135 & 751 & 7091 & 3341 & & 668 & 367 & 574 & 640 & 1053 & 1998 \\
\hline 53080 & 39603 & 37448 & 658 & 1497 & 7141 & 632 & 1774 & 492 & 1000 & 1631 & 2304 & 1999 \\
\hline 52840 & 52840 & 34195 & 384 & 18261 & 9900 & 348 & 1654 & 425 & 1170 & 1679 & 3085 & 2000 \\
\hline 54135 & 54135 & 37295 & 585 & 16255 & 8179 & 235 & 1189 & 720 & 1193 & 1475 & 3264 & 2001 \\
\hline 26679 & 52791 & 35696 & 622 & 16473 & 8742 & 264 & 1421 & 582 & 852 & 2359 & 2254 & 2002 \\
\hline 27571 & 61528 & 47380 & 743 & 13405 & 7766 & 238 & 1098 & 588 & 599 & 1888 & 1228 & 2003 \\
\hline 32281 & 63447 & 74315 & 768 & 15364 & 8121 & 244 & 1638 & 614 & 1030 & 1641 & 2076 & 2004 \\
\hline 32964 & 75193 & 56026 & 879 & 18288 & 9508 & 374 & 1951 & 800 & 1387 & 1923 & 2345 & 2005 \\
\hline 38048 & 82774 & 64104 & 888 & 17782 & 8658 & 754 & 3472 & 761 & 1394 & 1437 & 1306 & 2006 \\
\hline 31770 & 234488 & 212517 & 978 & 20993 & 8703 & 640 & 5739 & 787 & 1468 & 1917 & 1739 & 2007 \\
\hline 29251 & 97138 & 77047 & 1262 & 18829 & 8636 & 516 & 5260 & 645 & 1348 & 1121 & 1303 & 2008 \\
\hline 17011 & 74396 & 55999 & 520 & 17877 & 8005 & 294 & 5097 & 701 & 1330 & 1280 & 1170 & 2009 \\
\hline 13688 & 58291 & 39162 & 762 & 18367 & 8262 & 270 & 5223 & 777 & 1380 & 1326 & 1129 & 2010 \\
\hline 11172 & 48401 & 41932 & 328 & 6141 & 3200 & 73 & 976 & 505 & 431 & 426 & 530 & 2011 \\
\hline
\end{tabular}

1 - شرطه السياحة - احصاءات الهيئة الاقليمية لنتشيط السياحة بالفيوم

أفاق التنـمية: في محافظة الفيوم، مركز بحوث و استشـار ات التنمية، جامعة الفيوم بالتعاون مع محافظة

Fayoum J. Agric. Res. \& Dev., Vol. 26, No.2, July, 2012 


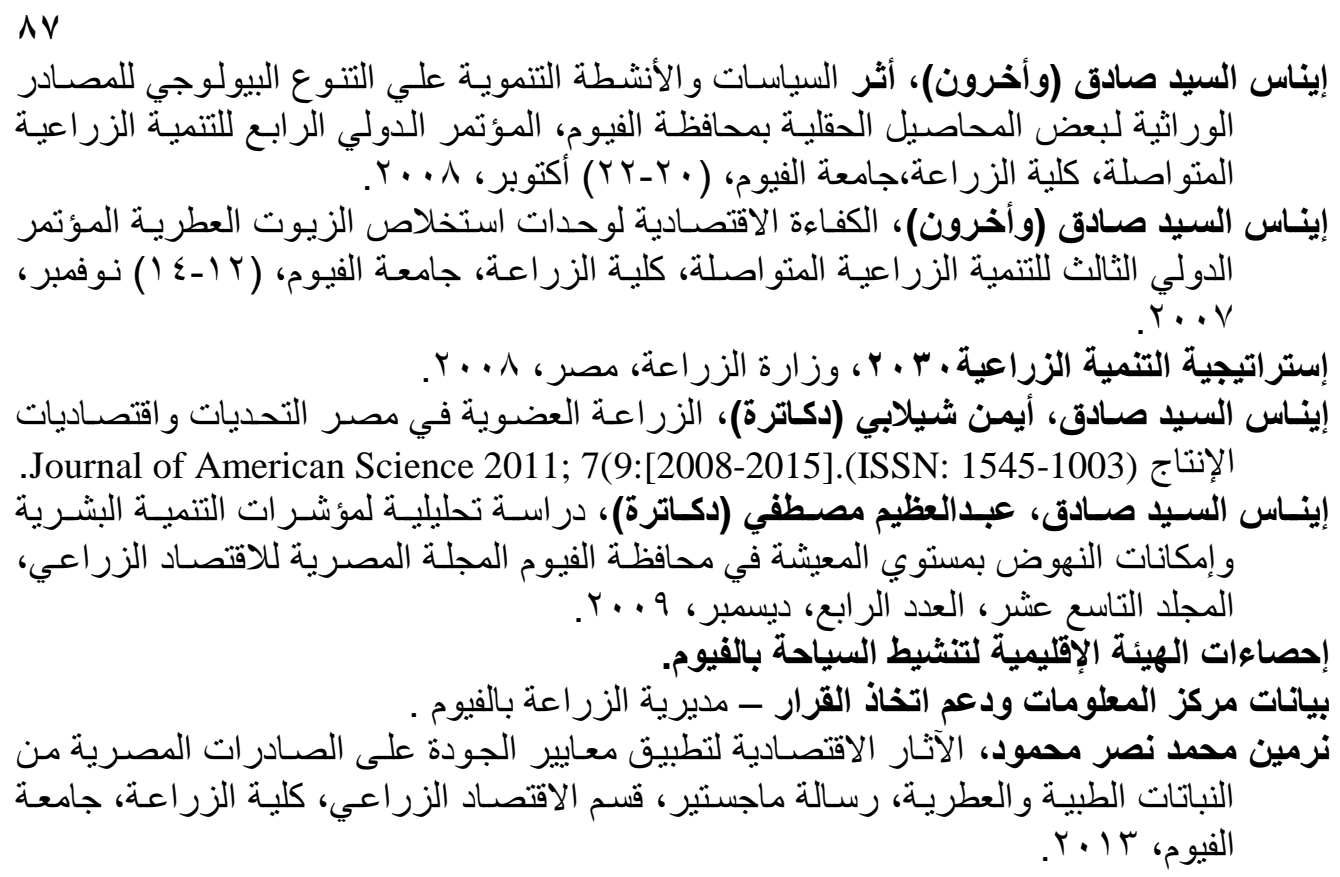

Guidelines for value chain analysis, Jon Hellin and Madelon Meijer, November, 2006.

Macfadyen, G. et al. Value-chain analysis of Egyptian aquaculture. Project report 2011- 54. The World Fish Center. Penang, Malaysia, 2011..

The Gambian Tourist Value Chain and Prospects for Pro-Poor Tourism Jonathan Mitchell and Jojoh Faal, Overseas Development Institute, March 2008.

Value Chain Analysis for Policy-Makers and Practitioners, Hubert Schmitz Institute of Development Studies, University of Sussex England, International Labour Organization 2005.

Value Chain Mapping Report, Upgrading Medicinal and Aromatic Plants Value Chain Access to Export Markets, UNIDO/ETRACE, July 2011.

\section{CLUSTERS CHARACTERIZATION AND VALUE CHAIN MAPPING OF THE MAIN ECONOMICS SECTORS IN FAYOUM GOVERNORATE}

Fayoum J. Agric. Res. \& Dev., Vol. 26, No.2, July, 2012 
$\wedge \wedge$

\section{Enas El-sayed Sadek \\ Professor of Economics, Faculty of Agriculture, Fayoum University. Director of Development Research \& Consultation Center.}

\section{Summary}

The study aims in general to map and characterize value chains of the main economic sectors in Fayoum governorate. This is through key economic sectors identification, and clusters characterization which can lead to the development in Fayoum governorate. In order to develop a vision to strengthen the value chain and help to raise the standard of living in the governorate.

It focuses on the value chain mapping of key economic sectors in Fayoum governorate at various levels including producers and local traders, exporters and service providers (the beginning of the elements of production and financing services and guidance on production and marketing). Data is collected through interviews and field visits to all groups within the value chain in order to analyze the complexity, interdependence and coordination among them to identify areas of strength and weakness, opportunities and threats.

This study shows that it requires interdependence between agriculture and tourism sectors through developing agro-processing and handicrafts to raise the standard of living. Integration enhancement is needed between industrial area and small industries to activate the role of this investment. This requires detailed study of the actual market demand and market needs for these products. In addition to studying the technical and economic opportunities to learn about the economic feasibility of the establishment for such projects in general.

Tourism is the most important economic sector in fayoum. Although it includes various tourist activities that feature the governorate, it needs to provide tourists with the service that they expect according to promoting tourism programs which meet their requirements. Competition and preference depend on cost and quality of services provided to tourists (travel cost, accommodation, food and drink cost and quality, shopping and all other services, qualified tourism guide, as well as people behavior and hospitality, infrastructure and communications services).

Fayoum governorate has competitive advantage in producing some agricultural products and small industries in specific places and villages. Also, it is characterized by the availability of production inputs, appropriate environmental conditions and inherited experience in the production of those products. Fayoum can achieve great successes in development of agricultural organic exports as it has adequate possibilities of expansion in organic agricultural production in general and develop the competitiveness of Egyptian agricultural exports to global markets.

Fayoum J. Agric. Res. \& Dev., Vol. 26, No.2, July, 2012 